DETERMINANTS OF STRESS IN MOTHERS

OF YOUNG INFANTS

Janet Younger

Richmond, Virginia

B.S.. Medical College of Virginia, 1967

M.Ed., University of Virginia, 1970

M.S., Virginia Commonwealth University, 1972

A Dissertation Presented to the Graduate Faculty of the University of Virginia in Partial Fulfilment of the Requirements for the

Degree of Doctor of Philosophy

Department of Education

University of Virginia

May, 1984 
揱

$$
\begin{aligned}
& 015 \\
& \text { d. } \\
& 1984 \\
& 168 \\
& 6094^{2}
\end{aligned}
$$


(C) Copyright by Janet B. Younger All Rights Reserved. May, 1984 


\section{DETERMINANTS OF STRESS IN MOTHERS OF YOUNG INFANTS}

101 mothers of poung healthy infants were studied to determine the factors that predict parenting strass at six to eight weeks post partum. Subjects completed the Parenting Stress Index, the California Psychological Inventory, a Social Support Checklist, and a Background Information Questionaire. The Background Information Questionaire measured the stressfulness of such childbearing circumstances as unplanned pregnancy, unwanted pregnancy, the rated stress of the pregnancy, complications of preqnancy and labor and delivery and the method of delivery. It also measured the nature and comparability of prior experiences and qeneral life experiences that might affect childbearing.

Results shown that stress can be predicted moderately well from a linear combination of stressors events with unwanted preqnancy, unplanned pregnancy, characteristics of the child and the rated stress of the pregnancy accounting for most of the explained variance. The mother's personality strength, social support and positive prior experiences were inversely related to parenting stress and mediated the effects of the stressor events. In linear combination, these mediating variables were found to significantly increase the accuracy of predicting parenting stress. Personality was the strongest mediating variable.

The results support current theoretical notions of stress as they might be applied in the situation of childbearing. They also have implications for clinical assessment and intervention. 
For the Graduate Faculty

of the

University of Virginia

Aproroved:

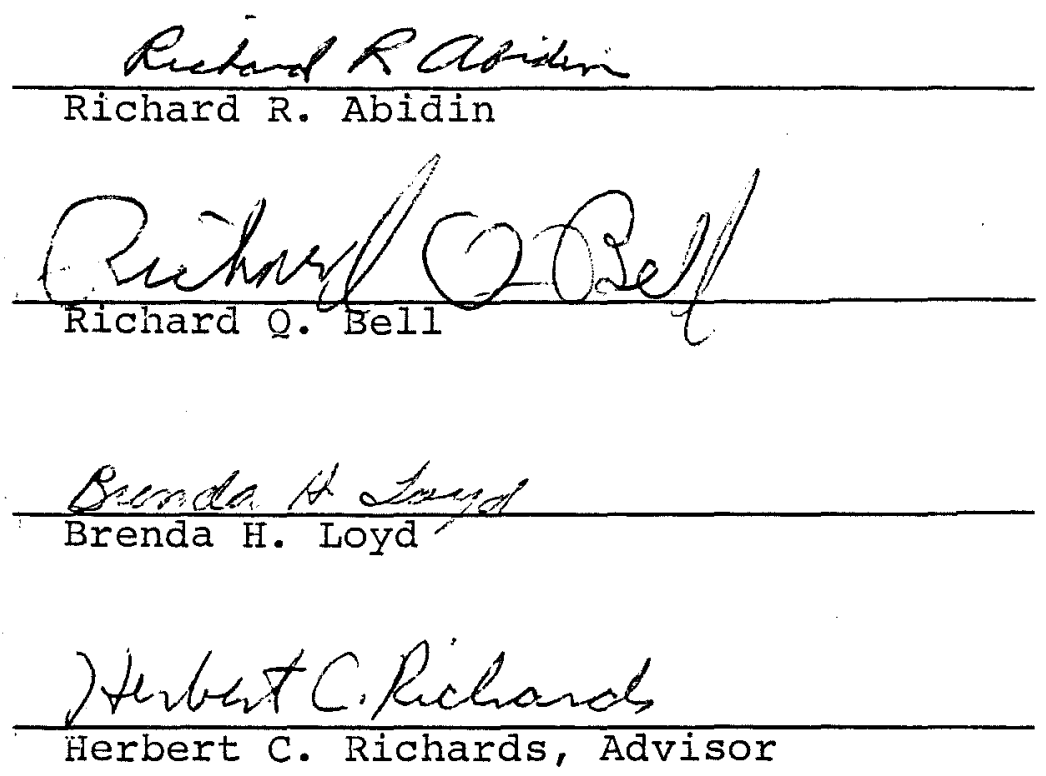

Determinants of Stress in Mothers

Of Young Infants

Janet B. Younger 


\section{ACKNOWEEDGEMENTS}

I want to express my appreciation to a few of those who contributed to the completetion of this aturlw.

The mothers who were the subjects of the study contributed several wours of theite tire in the widet of very demanding schedules that accompany caring for a young infant. Many of these mothers also wrote a note of additional information or comment that gave me a feeling of personal acfuaintance with them and added to ny interest in the studp.

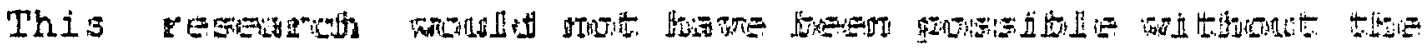
assistance of ten pediatricians in the Richmond area who took time from their practices to refer me their patients. It was also necessary for them to review each patient to assure that the baby was "normal" as specified by the study. Further. I have been very pleased to hear of their continued interest in the findings of the research and their interest in learning more about the methods used.

I am also grateful to members of the Department of Pediatrics of the Medical College of Virainia, Virginia Commonwealth University who helped me locate pediatricians who would cooperate in the study. Their recommendations concerning the potential value of this study to patients were clearly a factor in obtaining the support of the local pediatris community.

I am deeply indebted to my dissertation committee, each 
of whom made a valuable contribution to this study. Dr. Ricbard Abidin is to be commended for the development of the Parenting stress Index which I believe is a valuable tool in the promotion of healthy parenting. He also contributed his experience in the use of this instrument to the design and interpretation of this study.

Dr. Richard Bell has been a significant figure in my entire doctoral program. His interest and commitment to child development research is contagious. His personal contributions to the field in the area of the effect of the child's characteristics on his mother directly intiluenced this research.

Dr. Brenda Loyd has also been a key figure in my doctoral program. Her expertise in research and statistics has been very valuable. Her keen intelligence and thoroughness was much needed in achieving the more complex statistical manipulations of this study.

Dr. Herbert Richards gets my special thanks for having been a wondertul advisor. He is a gifted teacher who has a special ability to do exactly the right thing to enable a student to take the next step in learning. [ have heard it said that writing a dissertation is very much like delivering a baby and I would agree with that. In the context of this study it seems especially appropriate to say that Herb Richards made it a positive experience. 


\section{ACKNOWLEDGEMENTS}

\section{ABSTRACT}

I. REVIEW OF THE LITERATURE . . . . . . . . . . . . . . 1

Stress of Childbearing. . . . . . . . . . . . 3

The Delivery Experience . . . . . . . . . . . 7

Child Characteristics as a stressor . . . . . . . 10

Factors Influencing the Effect of Stress....... 12

Effects of Fersonality . . . . . . . . . . . . . 13

Effects of Prior Experience . . . . . . . . . . . 17

Effects of Social Support . . . . . . . . . . . . . 18

Summary . . . . . . . . . . . . . . . . . 27

Purpose of the Study... . . . . . . . . . . 28

II. METHOD . . . . . . . . . . . . . . . . . 30

Subjects...................... 31

Procedure ..................... 31

Instruments . . . . . . . . . . . . . . . . 32

Data Reduction.................... 43

Plan of Analysis................ . 51

III. RESULTS . . . . . . . . . . . . . . . 53

Hypothesis 1... . . . . . . . . . . . . 54

Hypothesis 2................. . 57

Hvpothesis $3 . . . . . . . . . . . . . .664$

other Interesting Findings . . . . . . . . . . 69

IV. CONCLUSION . . . . . . . . . . . . . 74

Stressors . . . . . . . . . . . . . . 75

Mediating Variables . . . . . . . . . . . . 76

Medlating of Stress . . . . . . . . . . . . 80

Implications of the Study . . . . . . . . . . . 81

Summary . . . . . . . . . . . . . . 85

REFERENCES . . . . . . . . . . . . . . 87

APPENDICES . . . . . . . . . . . . . . . 98

Appendix A: Letter to Mothers . . . . . . . . . 98

Appendix B: Letter from Pediatricians....... . 100

Appendix C: Support System Checklist . . . . . . . 101

Appendix D: Background Information . . . . . . . 103 
Appendix E: Intormed Consent ${ }_{\text {Appendix F: Intercorrelations of CPI Subscales : } 106} 107$

Appendix G: Intercorrelations of Stressor

Variables ............. 108

Appendix H: Intercorrelations of Social

Support Variables. . ...... 109

Appendix I: Intercorrelations of Experience

Variables. . . . . . . . . 110

Appendix J: Descriptive Summary of Reduced

Variables . . . . . . . . . . . 111

Appendix K: Descriptive Summary of CPI . . . . 112

Appendix I: Descriptive Summary of PSI . . . . . 113

Appendix M: Descriptive Summary of Social

Support Variables........ . 114

Appendix N: Descriptive Summary of Stressor

Variables . . . . . . . . . . 115

Appendix 0: Descriptive Sumary of Experience

Variables . . . . . . . . . . . 116

Appendix P: Major Obstetric Complications . . . 118 
LIST OF TABLES

Table

Page

1. Stressor Variables: Varimax Rotated Factor

Loadings . . . . . . . . . . . . . . . . .

2. Experience Variables: Varimax Rotated Factor

Loadings. .

3. Social Support Variables: Varimax Rotated Factor Loadings

4. Correlation of stressor Variables with Stress. .

5. Regression of Stressor Variables on Total Stress.

6. Correlations of CPI Sub-classes with Stress . .

7. Correlations of Experience Variables with Stress.

8. Correlation of social support Variables with stress

9. Multiple Regression Analysis of Total Stress with Moderator Variables Controlied . . . . . .

10. Multiple Regression Analysis of Parent Domain stress with Moderator Variables Controlled . . . . . .

11. Multiple Reqression Analysis of Total Stress with Stressor Variables Controlied... . . . . .

12. Regression Analysis of Parent Domain Stress with Stressor Variables Controlled........

13. Multiple Regression Analysis of Total Stress with Stressors and Moderator Variables Controlled 
CHAPTER ONE

REVIEW OF THE IITERATURE

Interest in the area of stress has resulted in

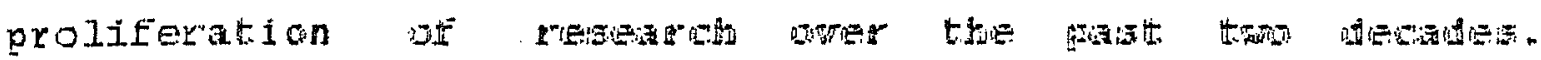
stressors are external events or conditions that impinge on the organism and require adaptation (Breznitz and Goldberger, 1982). An increasing number of events and conditions are now considered stressors, with such thinas as developmental or Life crisis events and environmental stimuli currently receiving much attention.

Some of the more challenging research on stress is in the area of personal and social changes in an individual's life. Whether a change brings foy or loss. it requires adaptation to new conditions and thus, is inherently stressful. Preqnancy, birth and childrearing have been identified as potentially stressful events. Although not an illness per se. pregnancy and childbirth are health changes that that clearly challenge the adaptive capacity physiologically, psychologically and socially. They carry. with them risks for a defined body of pathologic conditions (Nuckol1s. Cassel \& Kaplan, 1972). This study will apply the propositions of stress theory to childbearing in an attempt to better predict outcomes of this experience.

The effect of extremely traumatic experiences. such as wars. concentration camps and natural disasters initially 
motivated strexis renearch (Holroyd \& Lazarus, 1982). Howevew. since some people survived these dire experiences intact and in relatively good health, a move pervasive ingerest in the strengths of the human spirit and how they could be engendered developed.

Developmental psychology, through the work of Erikson (1950). proposed that growth may occur through crisis resolution. resulting in accrued strengths of the ego. Past sucessful experiences lead to future expectations of self-efficacy, which, in turn, lead to more vigorous and persistent efforts to master threatening tasks and situations (Moos \& Billings, 1982). Stress handled in this way may have humanizing and actualizing effects (Haan, 1982).

The long-term goal of studying stress is plainly a humane one--knowledge of how societies might organize themselves to avoid the unnecessary stresses that people experience and to buffer the inevitable stresses that citizens must suffer (Haan, 1982). A more immediate goal is to predict which people will be adversely affected by stressful situations. so as to intervene as quickly as possible (Appley \& Trumbu11, 1977).

Stressors may impinge on the organism, but do not entirely account for the effect on an individual. Why is it that among individuals exposed to a common stress. such as childbearing, some defend successfully with minimal effort. but others must mount a more heroic defense? 
Stress theory has evolved to explain differences in response to stressors. Early research efforts, such as the now famous work of Selye (1956), focused on the nonspecific general adaptation syndrome which occurred in response to any stressor. Later, Lazarus (1966) directed more attention to individual differences in appraisal of the stressful situations. Present emphasis $1 \mathrm{~s}$ on the interaction of stressor, individual appraisal, and coping strategy that is considered in the context of a specific situation and environment.

Childbearing is a developmental crisis that may facilitate personal growth or, if the crisis is poorly resolved. risk of pathology. The remainder of the literature will focus on factors that factors that produce stress and factors that may serve as assets in coping with stress. The Stress of Childbearing

Pregnancy and childbirth require massive physiological and psychological adjustments. In the case of a first baby. the transition to parenthood can be viewed as a developmental crisis.

A primary mechanism through which childbearing exerts its stressful effects is change. There are a number of pathways through which change can produce deleterious effects (Marris. 1974; Pearlin, 1982). Change can leave people with a sense of loss of control over their own destinies; it can undermine people's ability to predict their futures; it can 
erode the precepts by which people interpret and derive meaning from experience; and it may engender a profound feeling of loss of the past. leaving people in a state of bereavement. High levels of change experienced within a relatively short pexiod of time often have deleterious effects (Johnson \& Sarason. 1979). Thus, change per se is stressful regardiess of the desirability of the events (Sarason. 1980).

LeMasters (1957) was a pioneer in research establishing parenthood as a crisis. He interviewed 46 middle and upper class, educated couples with a first child five years old or under. He rated the couple's experience with first parenthood on a five point scale from "severe" to "no crisis." "Extensive" or "severe" crisis in adjusting to the first child was reported by $83 \%$ of the couples. This was true even when the pregnancy was wanted and the marriage was good.

A more recent study reported by Leifer (1977) supports LeMaster's finding. The major theoretical assumption was that preqnancy and early motherhood may be viewed as a series of developmental tasks, and that the way in which these are coped with will be predictive of adaptation to the maternal role. She collected data at seven points throughout pregnancy and the postpartum period. Findings indicated that adjustment to pregnancy and degree of personality integration achieved in early pregnancy was predictive of psychological growth and adaptation experienced throughout pregnancy and early 
parenthood (Leifer, 1977).

However, reporting the affective changes of the postpartum period, Leifer (1977) noted that the first two postpartum months were commonly felt to be periods of intense emotional stress. For more than two-thirds of the women. the early postpartum period was characterized by moderate to extreme negative affect; for only a few was the mood one of extreme contentment, and satisfaction. More than half the respondents felt their negative moods were more pervasive and intense postpartum than they had been during pregnancy. suggesting that the emotional crisis of the postpartum period exceeds that of preqnancy. The mood tone of most women was characterized by feelings of depression, anxiety over providing adequate care for the baby, and heightened emotional lability. When emotional support decreased, the period was experienced as even more difficult and was accompanied by feelings of aloneness and isolation. Towards the end of the second month postpartum anxiety decreased as competence regarding mothering ability increased, but boredom with the routine of child care and a sense of emotional constriction were now frequently experienced (Leifer, 1977).

With regard to the adaptations to motherhood. Leifer (1977) reported that during the early postpartum period most women experienced a decrease in confldence about their maternal abilities. The realities of coping with the new tasks of motherhood evoked feelings of inadequacy. By the 
late postpartum period, women who had been confident about their maternal abilities during pregnancy experienced an increased sense of competence: but for those who had been uncertain. feelings of inadequacy persisted. Thus the degree of confidence shown early in the preqnancy is an accurate predictor of confidence experienced at seven months postpartum. In adapting to the general life changes incurred by parenthood, the majority of women experienced moderate to high degrees of stress and maintained ambivalent or neqative perceptions about parenthood at seven months postpartum. More than two-thirds reported that parenthood was more stressful than they had anticipated because of the persistence of somatic symptoms and anxiety over performance in the maternal role, because they did not have enough help with either the baby or with household chores. or because long periods of being home alone with the baby evoked feelings of being burdened and tied down by the unrelieved responsibility. The principal areas of difficulty were lack of help in caring for the baby and home, curtailment of personal freedom. changes in marital relationships, as well as adaptations to the demands of the baby.

Despite the difficulty experienced in the early postpartum period, for almost two-thirds of the sample feelings of self-esteem were increased. The most characteristic feeling was one of growth and expansion of the self. So while most women experienced pregnancy and early 
parenthood as a period of psychological stress. only part of the sample concomitantly experienced a growing sense of adulthood and the personality integration suggestive of a new developmental stage. Thus, for some women regressive behavior appeared to be a reflection of rapid psychological changes which provided the necessary condition for new growth. However, other women experienced pregnancy and early motherhood as a period of emotional crisis and did not show signs of increased maturation or resolution of these conflicts (Leifer, 1977).

The Delivery Experience

The mother's attitude may also be affected by the method of delivery. In spite of a current trend toward family centered childbirth, there is a concurrent $r$ ise in the incidence of caesarean births. In the United States the rate of caesarean section has increased from 5\% in 1968 to $11.4 \%$ in 1976. to $15.2 \%$ in 1978 (National Institute of Health. 1982). In this social and historical context, it is not surprising that the reactions of women who plan a natural birth but deliver via caesarean section range from disappointment to postpartum depression reaching psychotic proportions (Lipson \& Tilden, 1980).

Surgery has been shown to have important psychological effects through the feelings it produces of loss of control over the body. Oakley gives as one of the main findings of her "transition to motherhood" project the gap that exists 
between expectations and reality, the whole birth process had contradicted the mothers" romantic expectation. "Childbirth" . oakley states. " is a life event with considerable loss and uncertain gain. The response may be hopelessness and its extent is determined by the amount of control people feel of their own lives--which for a time the mothers delivered by caesarean section were unable to do (Trowe11, 1982).

Studies indicate that the caesarean mother's perception of her experience is significantly less positive than is that of the woman who has delivered vaginally, especially her feelings about herself and her early feelings about her infant (Lipson \& Tilden, 1980; Affonso \& Stichler, 1978; Marut, 1978; and Marut \& Mercer, 1979).

In Trowe11's (1982) investigation of the effects of emergency caesarean section on the mother-child relationship. she noted there were differences in attitudes and behavior between the caesarean and a control group of mothers at one month and at one year. The mothers delivered by caesarean section had more doubts about their capacity to care for their babies. were more depressed and felt their babies did not become a person until later. They also found adjusting to the birth of their first baby and parenthood more difficult than the control group of mothers. However. the caesarean mothers were not different from the control mothers in the nature and degree of their psychiatric disturbance. but they took longer and had more difficulty in establishing a good 
mother-child relationship. They were more disinterested. indifferent to their babies and found the responsibility of parenthood more difficult to accept. They lacked confidence and the practical tasks of motherhood very quickly became overwhelming. Caesarean mothers responded to their babies more slowly and with less eye-to-eye contact. Many caesarean mothers reported that their baby had nothing to do with them ( Trowe11, 1982).

A number of variables in the Trowell study were crucial to women's experience of the caesarean birth. There were the woman's plan and expectations for natural childbirth, her relationship with her doctor, the amount of time she had to prepare for surgery, the reason for the caesarean, the extent of her labor. the presence of her husband during the surgery and recovery period, her contact with her infant, and any medical complications (Lipson \& Tilden, 1980).

Coping with the birth experience continues postpartum. There is a period of emerging awareness of the birth experience. The first weeks at home with a new baby are difficult for any parturient woman. For caesarean mothers. the difficulty is heightened by the conflict between round-the-clock care of a demanding newborn and the demands of recovery from major surgery. Women report the strong need to be taken care of, to be mothered and nurtured. Consistent with this need, women often experience disappointment in their mothering skilis, the development of which has been 
hampered by the post-operative recovery period. Aside from "normal" new motherlng difficulties, however, awareness of the meaning of the caesarean to the individual begins to emerge.

With any woman an important task is to reconstruct the childbirth experience, enabling her to integrate the experience and turn her energy to the task of mothering. Even after normal delivery, many women are distressed by forgotten or confused events, and will search their interpersonal environments for "missing pieces" (Affonso, 1977). Moreover, with caesarean mothers troubling questions arise. The facts of the surgery, including the indications for it, are now more critically reviewed. Memories of the caesarean, or specific feelings associated with it, may begin to emerge through dreams. Perceptions of stigma, feelings of failure. and self-image problems bother many women during this phase (Lipson \& Tilden, 1980).

Child Characteristics as a Stressor

The work of Thomas, Chess, and Birch (1968) on children's tempermental characteristics supports the contention that children's differences in activity level. mood, reqularity, and adaptability affect whether they are seen as "difficult" or "easy". Certain child characteristics or the way that child characteristics interact with parental expectations can be stressful (Bell, 1968, 1974, 1977) observed that a child's own characteristics contribute to the 
stimuli impinging on his parent and thus contribute to the way the parent relates to him. The effect the child has on the parent is most evident if he is premature, handicapped, ill, or exceptional in any way. An infant that requires more caretaking and provides less reinforcement to its parent is likely to be perceived as a greater source of stress. Subtle variations in his competence, assertiveness, and social response can also have significant effects on the parent, according to Bell.

The reciprocal effects of the parent-child relationship is crucial to understanding the potential stressfulness (Bel1,1977). A child's behavior keeps changing and requires the parent constantly to adjust. If the temperment or timing of the child's characteristics does not fit the parent's, these adjustments become more difficult. A parent's response to the child, instead of reflecting sensitivity to the child's developmental or individual needs can become limited to strategies that attempt "to maintain child behavior within an optimum range" $(1977, p .65)$. When parental behavior has this goal instead of the goal of meeting the child's needs, often the child's demands become even more persistant and aversive (Ainsworth and Bell, 1979).

Thus in the present study, it is expected that untoward experiences in pregnancy or puerperium will be related to early parenting stress. Further, characteristics of the child that are particularly "difficult" or are out of synchrony 
with those of the mother are also expected to be related to stress.

\section{Factors Influencina the Effect of Stress}

At least five factors influence a person's response to a call for action: (a) the nature of the task. (b) the skills available for performing the task, (c) personality characteristics or dispositions to appraise the task in particular ways or to respond with self-preoccupation. social supports. (e) the person's history of stress-arousing experiences (Sarason, 1980: Rabkin \& Streuning.1976).

McGrath (1970) suggested that assimilation of undesirable circumstances is more difficult for people when (a) the bad event is not anticipated or their hopes for good news have been dashed, (b) the onset is out of their control, (c) the conditions of their situation are ambiguous. (d) unpleasentness is anticipated, (e) the situation resembles other poorly resolved events, (f) the person is already stressed by other matters, and ( $g$ ) efforts to secure pertinent information are defeated.

In addition, accommodations to stress are more difficult when (a) one has little or no possibility of diminishing the stress--its outcome is beyond one's control (Seligmann, 1975), (b) stress is intense, (c) stressful experiences closely follow one another, and $(d)$ one has had no previous experience with the particular kind of stress.

Certain factors can mediate the effects of stress. 
Psychological stress requires a judgment that environmental and/or internal demands tax or exceed the individual's resources for managing them (Holroyd \& Lazarus, 1982). Thus, stress is in the mind of the beholder (Cohen. 1980). The role of the individual as a mediator of stress has been emphasized by Lazarus (1982). Stressful circumstances do not take their toll from a passive individual, but from one who is imbuing them with personal meaning and struggling to control and master these circumstances. Because these mediating psychological processes are important determinants of the stress experience, it is inevitable that situations will be encountered in which there is little or no relationship between the severity of the adjustment demands impinging on the Individual and the adaptational consequences of these demands. Thus, claims Lazarus, our efforts to understand the impact of stress on human adaptation will be heavily dependent on conceptualizing these mediating psychological processes.

\section{Effects of Personality}

Psychological characteristics operate directly on the appraisal process and predispose the individual to perceive a particular class of events as highly threatening to personal security. More general cognitive schemas (e.g., self-efficacy expectations) act as psychologically predisposing factors by exerting their influence on the appraisal of life events. Thus, the appraisal process and general cognitive schemas act 
psychologically to moderate the impact of the environment on individuals (Depue, 1979).

The readiness to become jittery, agitated, and preoccupied with frightening images in response to a threat is related to a number of personality variables. Among the predisposing attributes are chronic anxiety neurosis, low eqo strength, low self-confidence, low problem-solving ability. and low capacity for developing or using a network of social supports (Janis, 1982). Janis further describes a state of hypervigilance in which the person repeatedly displays the characteristic symptoms of psychological trauma--trembling of the hands, preoccupation with possible recurrences of danger, and terrifying nightmares and intrusive daytime visions in which traumatic events are reexperienced. Among the factors most frequently implicated as antecedents of hypervigilant reactions are lack of contact with family members or other supportive persons, restrictions of activity, lack of perceived control over dangerous events, and lack of preparatory information about the stressful events to be expected and about what to do to build up one's coping skil1s. Defensive avoidance of early warnings about a given threat may be regarded as psychological reactions that increase the probability of hypervigilance in response to a subsequent stressor (Janis, 1982).

The probability of hypervigilance is decreased by benion preexposure to the threatening situation. stress inoculation 
via preparatory communications, and controlled breathing and relaxation procedures designed to moderate physiological responses to emotion arousing situations. The underlying principle is that accurate preparatory information about an impending crisis allows people to anticipate the loss, to start working through their anxiety or grief, and to make plans for coping adequately (Janis, 1982).

Personal coping resources, such as development of trust and autonomy, accrued during the childhood and young adult years are integrated into the self-concept and influence the process of coping in adulthood and old age. This perspective assumes that adequate resolution of the transitions and crises that occur during the life cycle leads to coping resources that can help resolve subsequent crises. Successful encounters with stressors build a sense of efficacy and eqo integrity (Moos \& Bilings, 1982).

General coping resources also include self-esteem, eqo identity, competence motivation, novelty needs, and stimulus seeking behavior (Haan. 1977). These resources can affect the appraisal of potentially stressful situations, as well as the selection of coping responses to handle such situations. For instance, a sense of competence may lead a person to perceive a potential stressor as less threatening and to choose a reality oriented coping response that fosters a successful outcome. Coping resources can also help people anticipate and take action to avoid expected social stressors (Moos \& 
Billings, 1982). Higher levels of ego development are also moderately associated with a greated variety and effectiveness of coping strategies (Haan, 1977; Moos \& Billings, 1982).

Other personality attributes also influence coping. Johnson and Sarason (1978) found that the relationship between recent stressful life changes and anxiety and depression was stronger among persons with an external as compared to an internal locus of control (Moos \& Billings, 1982).

Persons who turn their hostility inward are likely to be higher in anxiety, guilt, and feminine sexual identity, to show greater decreases in estimates of their own ability after a failure experience, and to fail to take appropriate precautions against unwanted pregnancy (Moos \& Billings, 1982).

In summary, the individual differences in reactions to stress are probably the result of these factors: (a) The significance of the event to the individual which will depend on his appraisal of the circumstances surrounding that event and his prior experience with that event, with similar events and with symbolically related events. (b) Personality attributes of the individual; a general sense of competence and self esteem are assets, anxiety proneness obviously acts as a multiplier of the arousal produced by any stimulus and is an important factor in persons who habitually cope poorly 
with stress. Thus, in the present study, the above factors of personality are expected to mediate the effects of stressors. Effects of Prior Experience

Prior experience may also mediate effects of stress. Investigators are interested in whether repeated exposure results in immunization, habituation, or breakdown. Important determinants seem to be the duration of exposure, the interstressor interval and the dosage level of repeated stressors (Breznitz \& Goldberger). When increased rate. dosage and duration of exposure combine, the system is tipped toward breakdown.

Dohrenwend and Dohrenwend (1978) have emphasized the importance of a person's previous history of dealing with stressors. Prior exposure to specific stressors may lead to habituation so that later experiencing of these same events results in lower levels of emotionality. In other words, the degree to which individuals are negatively affected by life stress probably depends in part on whether they have had a history of experiencing similar stressors in the past. Prior experience may be most important because it leads to development of coping skills. According to Johnson and Sarason (1979), there have been no life stress studies designed to investigate this relationship.

Prior experience with the task, the stressor and/or the situation. attenuates the effect of stress (McGrath, 1970). Training, in the sense of deliberate practice in performance 
of the correct responses, appears to be a blessing with respect to alleviation of stress effects (McGrath. 1970). Failure breeds failure. The experience of fallure on a task is stressful in itself and has a number of effects that subsequently lead to decreased performance effectiveness (McGrath, 1970). If the prior experience is negative, it will increase stress and degrade performance. If the prior experience is successful, or otherwise leads to learning, mastery, or adaptation, stress will be decreased and its negative effects on task performance will be attenuated (McGrath. 1970).

In the present study, prior experience with childbearing, if it was positive, is expected to mediate the effects of stressors.

alleviation of stress effects (McGrath, 1970). Failure breeds failure. The experience of failure on a task is stressful in itself and has a number of effects that subsequently lead to decreased performance effectiveness (McGrath. 1970). If the prior experience is neqative, it will increase stress and degrade performance. If the prior experience is successful. or otherwise leads to learning, mastery, or adaptation. stress will be decreased and its negative effects on task performance will be attenuated (McGrath. 1970). In the present study, prior experience with childbearing, if it was positive, is expected to mediate the effects of stressors. Effects of Social Support 
of key importance for coping, according to Coelho (1980). Is existential education for and experiences in the development of group consciousness and self-continuity. For thousands of years in agricultural settlements, education and experience provided the tools for the young in learning versatile behavior repertoires for coping with crises and changes in growing up. These models were tested and transmitted over a long period of time in small group contexts and in a diversity of environments. They appear to have worked well in adapting values and shared meanings of life for generation after generation, as each one prepared the next for the major transitions of the life cycle; birth. puberty, marriage, old age, bereavement, death, and burial (Coelho, 1980).

These institutional values and meanings were encoded in the support systems that served as a vehicle for maintaining socially adaptive behavior. By linking individuals together in a community of several generations, the support systems guided people to anticipate separations from one social order and reintegration into another and to promote self-continuity despite the changes from one stage to another in the cycle of life (Coelho, 1980).

Tolerance for change therefore, may be strengthened by a three generation family support system, which according to Caplan, meets the continually developing biologic-psychological-economic needs of individual members 
of the family and buffers the individual from exorbitant external demands (Coelho, 1980).

Thus, evolution has preserved a system wherein adaptation to conditions of the environment is facilitated by the cooperative efforts of the human community. One mechanism for this is the provision of culturally mandated skills necessary to solve problems. Another mechanism is social networks. which provide such interpersonal resources as emotional understanding, cognitive guidance, and tangible support. Environmental resources can affect appraisal of threat, as well as the choice, sequence, and relative effectiveness of coping responses (Moos \& Billings, 1982).

Bowlby (1973) contended that human beings of all ages are happiest and most effective when they are confident that trusted people will come to their aid should difficulties arise. Such trusted people provide a secure base from which to operate and constitute social support for the individual.

Research of life events and their stressful effects has been strongly affected by theories dealing with the moderating effects of perceived social support (Sarason \& Sarason. 1981; Magnusson, 1982). Cassel and Henderson have reviewed a wide range of studies that indicate that the social support provided by primary groups serves as a protection. "buffering or cushioning the individual from the physiologic or psychologic consequences of exposure to the stressor situation". The effects of stress can be exacerbated 
or tempered by varying the person's soclal supports (Brown, 1978; Cobb, 1977; Haan, 1982). Social support depends upon perception of the social network as containing individuals in whom one can confide and on whom to rely (Lieberman, 1982). But, it is not the total amount of help that is salient, but rather the fit between a particular kind of problem and the help provided.

The role of social supports in the lives of pregnant women was studied, with complications of pregnancy serving as the dependent variable (Nuckolls, Cassel \& Kaplan, 1972). The women were assessed in two ways: (a) frequency and severity of recent life changes and (b) social supports--people with whom the women were close, from whom they obtained affection, and on whom they could rely. Women who had many social supports had significantly fewer pregnancy complications than women who had relatively few supports. This relationship was particularly dramatic among women who had experienced high levels of life change.

A different strategy for studying the role of social supports was used by Reibstein (1981). A sample of 236 first-time mothers over the age of 25 was selected from women who had participated in Lamaze instruction. Aproximately half the participants joined mother's self-help groups subsequent to the birth. The participants were highly educated, upper-middle class women who had considerable investment in their work roles. Reibstein hypothesized, based on a model of 
role learning interactions that the relevant social resource would be peer support. Indices of peer interactions were developed to indicate opportunities for modeling with women like themselves; discussions and ventilation of feelings about role problems; and approval for performance in the new role. The extent to which peers, the respondent's mother, and mother-in-law offered such opportunities was assessed. Husbands' support and affirmation of the mothering role were also determined. Outcomes were assessed by measures of maternal role strain and role dissatisfaction. However. no appreciable relationship between peer group interaction and maternal dissatisfaction or maternal role strain was found. In fact. the more women discussed and ventilated their feelings about the maternal role, the more likely they were to be distressed and to show strain.

According to Leiberman (1982), what is most impressive in the findings was the strong and consistent effect of the marital relationship on women's well-being. For those women whose husbands did not provide the needed resources, there was no evidence that suggested that other resources could substitute.

A distinction is usually made between instrumental support, consisting of help with the tasks that are generated by the stress events, and expressive support, congisting of help with feelings aroused by the event of its consequent tasks (Gore, 1981). Satisfaction with may be a consequence of 
the service that is provided, or a sense that support, when needed, will be available, yielding a generalized sense of security (Gore, 1981). This sense of security closely approximates features of Cobb's (1976) two-faceted definition of support. One the one hand, support is information. But it is information that results in people believing they are cared for and loved, or esteemed and valued, or that they belong to a network of community and mutual obligation.

Andrews, Tennant, Hewson and Vaillant

investigated the risk of psychological impairment in members of a suburban community in relation to measures of life event stress, coping style, and crisis support. Social support and coping style were hypothesized to be factors in the causative model of "stress-arousal-iliness". either by acting independently of, or by moderating the effects of life event stress. Individuals rated their social support systems on availability of crisis support, neighborhood interaction, and community participation and responded to a questionnaire designed to measure habitual coping styles. Psychological impairment was assessed by a questionaire designed to detect nonpsychotic psychiatric cases. When the effects of the three variables were combined, the persons in the ideal situation had an impairment risk of 13.8 per cent, half the risk of the general population; whereas those in the least ideal situation of high stress, poor crisis support, and poor coping had a risk of 43.3 per cent, nearly double that of the 
general population. Rather than coping and social support mediating effects on life stress and the risk of psychological impairment, the results showed an additive effect. No specific interactive effect was evident; that is. good crisis support and good coping did not produce their effect because of their ability to detoxify the effects of high stress, but rather, because crisis support and coping style were independently related to neurosis. The authors thought these results could be influences by the "multiplier effect" of an individual's personality on his perception of stress or support, and on the coping styles he is likely to use.

Henderson (1977) examined adults' needs for attachment. He observed that four conditions of attachment differentiated women according to their likelihood of developing psychiatric disorder in the face of adverse events. These factors were: loss of the person's mother in childhood, having three or more children under 14 at home, lack of full or part-time employment, and lack of an intimate or confiding relationship with a husband or boyfriend. Conversely, a close relationship with a husband or boyfriend was found to provide almost complete protection in the face of adverse life events or difficulties. He concluded that the need for "affectively positive interaction"continues throughout the life span. Henderson suggested that this interaction is termed "support" when one is under stressful conditions. (Henderson,1977) 
Further research is needed to determine what aspects of attachment may be causally related to resistance to stress. The internalized attachment relationship may be the bridge between internal, coping abilities and perception of access to social support if individual responses are not enough to overcome particular stressors.

A good example of the research dilemma inherent in attempting to measure social assets in resisting stress is the controversy over whether quantity or quality of available social relationships is the crucial dimension of social support. A few recent investigators (Zimmerman, 1979; Wilcox, 1979; and Holahan \& Moos, 1979) have criticlzed previous researchers for failing to distinguish between quantity and quality of social support. They have attempted to study the comparison of number of others with quality of support. However, the results of these studies all rest on individual perceptions of both quantity of quality and therefore, may be reflecting personality "fllters" as well as social assets.

Wilcox (1979) hypothesized that under conditions of minimal life stress, social support has little or no effect on psychological adjustment, but that as stresses accumulate, the buffering effect of social support becomes evident. Wilcox had 320 subjects complete a scale that assessed emotional, tangible, and informational support and the number of closes friends available to the subject. When a self report index of psychological adjustment was used as the 
criterion, the results showed that the quality of support was more highly related to resistance to psychological distress in the face of life changes than quantity of support expressed in numbers of friends.

Holahan and Moos (1979) were interested in the relationship among quantity and quality of social support, negative life changes, and psychosomatic or psychological distress. They used the Family Relationships Index to measure support quality. Quantity of support was measured by a traditional network approach. Subjects consisted of 267 male and 267 female adults, and results were analyzed by sex and employment status. For unemployed women, self reports of negative life changes, network supporters, and family relationships together accounted for 53\% of the variance on the psychological distress checklist and $63 \%$ of the variance on the psychosomatic distress checklist. The authors concurred that the relationship between life stress and social support is additive.

In summary, social resources can influence both the occurrence and the effects of stress in a variety of ways: (a) Social resources can decrease the likelihood of the occurrence of stressful events. (b) If the event occurs. interaction with significant others can modify the individual's perception of the particular event and mitigate the stress potential. (c) stress levels are partially contingent on the degree to which a potentially stressful 
event alters role functioning. Social resources can alter the relationship between role strain and the stress inducing event. (d) Social resources can influence coping strategies and modify the linkage between stress event and effect. (e) To the degree that stressful events erode self-esteem and feelings of personal mastery, social resources can modify such effects. (f) There may be a direct influence of social resources on adaptational level (Lieberman, 1982). Therefore, in the present study, social support is predicted to mediate the effects of stressors.

Summary

The transition to parenthood is a stressful one. Theory and research in the area of stress produce certain propositions that may be applied to the stress of chlidbearing. Specifically, events will be more stressful if they are unexpected or uncontrolled, if stresses occur at frequent intervals, if the event is particularly severe or prolonged or if there is no previous experience with that type of stressor or if that experience is negative.

Individual personality, prior experience and social support all potentially mediate stress. Jenkins (1979) asserts the different capacities of individuals to adapt to stress is analogous to the infectious disease concept of "host resistance". The counterparts to host resistance at the psychological level, according to our theory, are ego strength, problem-solving ability, flexibility, experience, 
and social skills. At the interpersonal level, the adaptive capacity of the individual is raised by positive primary relationships and one's network of social supports (Jenkins, 19791 .

An adequate life event study should therefore: (a) determine the occurrence of the event and allow for the significance of the event to the individual; (b) measure the multiplier effect of relevant personality attributes; (c) identify the likely coping resources; and (d) identify the extent of crisis support used, before attempting to predict cases of psychological illness. The significance of such a study lies not so much in the prediction of illness, but more in delineating the relative importance of the various protective assets (Andrews, Tennant, Hewson \& Vaillant; 1978).

\section{Purpose of the study}

The purpose of the study is to determine the factors that predict stress in mothers of infants six to eight weeks of age. The hypotheses are as follows: Stressful events such as unplanned pregnancy and medical complications, particularly emergency cesearean section. will be positively correlated with stress. Prior childbearing experiences, if they were perceived positively, will be inversely related to stress. Social support will be inversely related to stress. The following attributes of the mothers personality will be inversely related to stress: interpersonal adequacy and 
soclalization, tolerance, good impression, achievement via conformance, achievement via independence, intellectual efficiency. psychological-mindedness and flexibility. And, ego strength is predicted to be inversely related to stress. Finally, experience, soclal support and personality are predicted to mediate the effects of stress. 
METHOD

The methods employed in this study are designed to identify the effects of stressors as they are mediated or potentiated by the situational context in which they occur. stress cannot be meaningfully investigated and understood without reference to the specific characteristics of the situation in which the behavior is observed (Magnusson. 1982).

A number of variables must be measured and analyzed to examine the stressful situation in context. Therefore, a multivariate approach will be used because it is best suited to the conceptual model of the study. Melick. Logue \& Frederick (1982) argue that analytic strategies that adopt a multivariate rather than a univariate approach are especially important in order to determine the joint effect of many independent variables and to control for confounding factors. Situational circumstances often act to reduce the effects of stress. Stokols (1979) supports this viewpoint and adds that the multivariate mediation of stress warrants explicit consideration. Lack of attention to moderator variables is a major drawback of much of the research to date (Johnson \& Sarason. 1979). 


\section{Subjects}

Subjects were 101 mothers of young infants. Only mothers of term infants with no known abnormalities were included. The mother's socioeconomic status was sufficient to afford private pediatric care. These limitations on population are designed to eliminate certain experiences already known to be important stressors, namely abnormalities and socioeconomic disadvantage (Haan, 1982). All infants of these mothers were receiving care from pediatricians in Richmond, Virginia and were born in hospitals in the metropolitan Richmond area.

The subjects were predominately white $(80 \%$ white, $20 \%$ black). The age of these mothers ranged from 17 to 40 . The mean age was 27 with a standard deviation of 4.8 years. The subjects were relatively well educated with almost one-third having completed college or graduate school. For $59 \%$ of the subjects, this pregnancy was their first, with $29 \%$ having one other child and $13 \%$ having more than that.

\section{Procedure}

Mothers referred by pediatricians received a letter from the investigator and the pediatrician providing the pertinent information about the study and asking for participation (Appendix A; Appendix B). Subjects were asked to complete the Parenting Stress Index (PSI), the California Psychological Inventory (CPI), Social Support Checklist (Appendix C). Background Information (Appendix D). Informed consent and consent for the investigator to review the medical records of 
the mother and baby were also be obtained (Appendix E).

The PSI was completed when the child was six to eight weeks old. This age range was chosen to eliminate the physiological and hormonal influences on the mother that would be present earlier and because crisis clinics base their operation on the accumulated wisdom that stressed people adopt, usually by six weeks, some solution to the problems they are experiencing (Haan, 1982). Thus, from a theoretical standpoint this represents an attempt to measure stress while still in the midst of the stressful experience. yet with behaviors sufficiently stabilized to have predictive value for later functioning. This type of within-situation measurement probably has the greatest payoff for research because reveals more about how people actually behave in stressful circumstances (Hann, 1982).

Instruments

Measurement of Parenting Stress (dependent variable). The Parenting Stress Index (See Appendix A) was developed by Burke and Abidin (1978). The PSI was designed to be an instrument whose primary value would be to identify parent/child systems which were under stress and at risk for the development of dysfunctional parenting behavior (Abidin. 1973). It is also a useful guide for determining whether professional intervention is needed. The PSI is a clinical and research self-report instrument. Its 101 Likert-type items are designed to be completed by parents with a fifth 
grade reading level in 25 minutes or less.

The PSI yields a total score, three domain scores and fifteen subscale scores. The domains are (a) Child characteristics, (b) Parent characteristics, and (c) Situation and demographic factors. The Child domain subscales Include: child adaptability/plasticity, acceptibility of child to parent, child demandingness/degree of bother, child mood, child distractibility/activity, and child reinforces parent. The Parent Characteristics Domain includes: parent depression, parent attachment, restrictions imposed by parental role, parent's sense of competence, social isolation, relationship with spouse, and parental health. The Situational/Demographic Domain includes: life stresses and situational factors. The domain and subscale scores assist in identifying the sources of stress.

Abidin (1983) reported reliability and validity data for the PSI based on a sample of 534 mothers and children between the ages of 1 month and 10 years, sixty percent of the children were younger than three years old. Internal consistency alphas ranged from .6 to .9 for the subtest and domain scores, and test-retest reliabilities ranged from .7 to .9 for three to four week interval, and from .5 to .85 for a one year interval.

The validity of the PSI is in the process of being established at 23 universities and medical centers in the United States and Canada (Abidin, 1983). Nineteen research 
projects involving the PSI have already been completed. Zimmerman (1979), for example, found that 10 of the 20 scores on the PSI were significantly higher in mothers whose children had cerebral palsy versus a matched control group of mothers whose children had no known psychological or physical abnormalities. The pattern of differences was also meaningful. since nearly all the diffecences were found in the Child Characteristics Domain.

Greenberg (1983) reported that the PSI discriminated between a clinical sample of parents of mentally retarded children and the normative population. The study also demonstrated a pattern of stressors emanating from the Child Characteristics Domain as would be expected with physically handicapped children.

Lafiosca (1981) explored the concurrent validity of the PSI by comparing parents of a matched sample of normal children with an unselected group of parents who brought their child to a child development clinic for evaluation. The Child Domain of the PSI was correlated with the Child Behavior Problem Checklist subscales lquay and Peterson. 1979). with correlations ranged from .53 to.63. The Parent domain score was correlated $(r=.68)$ with the the State-Trait Anxiety Scale (Spielberger, 1970). The discriminant validity was supported by the finding that the PSI correctly identified $100 \%$ of the normal children in the study and $60 \%$ of the parents of the children seen at the 
child development clinic when the ninetieth percentile of the PSI total stress score was used as a cutoff.

Hamilton (1980), in a study of 37 mother-infant pairs. found the PSI not to be effective in itself in discriminating between infants showing secure versus anxious attachment as defined by Ainsworth (1978). However, when the results of PSI were combined with the CPI (Gough, 1975) and a discriminant analysis conducted, it was possible to correctly classify $75 \%$ of the mothers in terms of their infants' category of attachment.

Abidin (1982) provided further evidence of validity in a study of parenting stress and the utilization of pediatric services. He found that health care services were more often sought for the treatment of injuries and accidents to children of high and low stress mothers than moderate stress mothers. No differences were noted for other types of medical problems. These findings suggest that mothers with low stress (detached) and mothers with high stress (disorganized) seem unable to provide the attention needed for adequate child care. leading to accidents in their children.

For most of the analyses, the total PSI score was used as the dependent variable. However, since the PSI domain scores are constructed to determine the source of stress. it was useful in this study to consider the characteristics of the child as one of a number of potential stressors. Therefore, for some of the analyses, the dependent variable 
was the parenting domain score and the child domain score was one of a number of independent variables.

The situational/Demographic Domain scale was grouped with the stressor variables, to be described later, and used as an independent variable for the purpose of measuring other Iife stressès.

California Psychological Inventory (CPI). The CPI is composed of 480 statements which participants mark "True" or "False" based on whether they feel the statements are true of them. CPI yields 18 raw scores which are converted to standard scores, each with a mean of 50 and a standard deviation of 10. The inventory is intended for use with non-psychiatrically disturbed subjects.

The 18 scales are intended to assess different facets of the personality that are important for social living and interaction. These facets are also very important in parenting. Each scale is designed to forecast what a person will say or do under defined conditions, and to identify individuals who will be described in characteristic ways by others who know them well or who observe their behaviors in particular contexts (Gough, 1975).

According to Haan (1977), most of the standard CPI scales do not appear on their face to measure psychological processes. Gough had wanted to measure folk concepts about personalities, but the line of demarcation between process and personality is sometimes thin. Several of his scales do 
seem to measure coping processes, namely, tolerance, good impression, achievement conformance, achievement independence, intellectual efficiency, psychological mindedness, and flexibility. In addition, Gough developed a modernity scale that measures the extent to which people favor social change and experimentation and indicates whether they are optimistic about the future and their capacity to cope with new experiences. Persons with high scores on modernity should handle stress differently than their low score counterparts (Haan, 1982).

In addition, performance on certain scales has been shown to be associated with patterns of emotional control (Byrne, 1964). Byrne, Golightly, and Sheffield (1965) found that high scorers on the sociability, self-control, Well Being, 'Tolerance, Good Impression, Achievement via Conformance and Intellectual Efficiency scales tended to use repressive defenses. In a separate study, Megargee, Cook, and Mendelsolin (1967) found an association between overcontrol of angry Impulses and patterns of response on the Self-control, Good Impression and Self-Acceptance scales.

The scales are grouped into four broad categories for interpretation (Goughh, 1975 p. 5). These are:

Class I. Measures of Poise. Ascendancy, Self-Assurance, and Interpersonal Adequacy

1. Do Dominance

2. Cs Capacity for status 
3. Sy Sociability

4. Sp Social Presence

5. Sa Self-acceptance

6. Wh Sense of Well-being

Class II. Measures of socialization, Responsibility. Intrapersonal Values, and Character

7. Re Responsibility

8. So Socialization

9. Sc Self-control

10. To Tolerance

11. Gi Good Impression

12. Cm Communality

Class III. Measures of Achievement Potential and Intellectual Efficiency

13. Ac Achievement via Conformance

14. Ai Achievement via Independence

15. Ie Intellectual Efficiency

Class IV. Measures of Intellectual and Interest Modes

16. Py Psychological-mindedness

17. Fx Flexibility

18. Fe Femininity

Test-retest reliability has been determined for 200 male prisoners and 226 high school students. Median reliabilities were .80 and .65 in the two groups respectively. The test-retest reliability in the prisoner group are as high as those generally found in personality measurement. The more 
modest reliabilities among high school students may reflect maturational differences (Gough, 1975).

In summary, the CPI is a commonly used measure of personality that yields 18 scales, 4 sub-classes, and a total personality score.

Background Information. An 18 item questionaire was designed to measure the stressfulness of childbearing circumstances and the protection afforded by comparable prior experiences and general life experience (See Appendix D). Respondents were asked to to rate the importance of the events to them. This method of judging cognitive appraisal of events has been advocated by Brown (1981). Such ratings go to the very heart of cognitive appraisal. One mother may have complications of pregancy and perceive the situation as very stresstul. Another may have the same complications and not. Research of stress in context required that these appraisals be known before attempting to predict outcome. Two kinds of data were obtained from this questionaire:

Stressors. Seven items on the Background Information questionaire indicated events that either the literature or logic suggests might produce stress in the post partum or early parenting period. These items were planned pregnancy (item 3)), wanted pregnancy (item 4), the rated stress of the pregnancy (item 5), the rated stress of the labor and delivery (item 6), complications of pregnancy (item 11). complications of labor and delivery (item 12), the method of 
delivery (1tem 13). Other Life Stressors, a subscale of the PSI was also included in subsequent analyses as a measure of stress.

The scoring of the seven stressor variables taken from the Background Information questionaire is indicated by the number in parenthesis next to each response (Appendix D). The highest number in each item was assigned to that response which is theoretically most stressful. Complications of pregnancy (Item 11) was scored as follows: no complications, 1; minor complications not requiring hospitalization, 2; complications requiring hospitalization, 3. Complications of labor and delivery (Item 12) was scored as follows: no complications, 1; minor complications, 2; major complications as 1 isted in (Appendix P), 3.

Experience Variables. Six items taken from the Backgroun Information questionaire were indicators of experience. They were: employment for a period of at least two years (item 17). training for a specific occupation for at least two years (item 18), number of other children (item 2), Lamaze training (item 9), prior pregnancy experience (item 7) and prior labor and delivery experience (item 8). Three other items that were indicators of experience were taken from the PSI. They were: age, mother's education and father's education.

Two of the items just mentioned (items 7 and 8 ) differed from the others in that they were designed to measure the 
comparability of prior experience. Respondents were asked to compare the present pregnancy, or labor and delivery, with a prior experience and to indicate whether the prior experience was positive and similar. It was predicted that the most protective experiences would be those in which the prior experience was both positive and perceived to be similar to the present experience and the least protective situation would be the dissimilar and negative comparisons. McGrath indicated that experience, if it is specific to the stressor, if it is positive and if it is perceived to be similar to the present situation is protective.

The scoring of the experience variables is indicated by the number in parenthesis next to each response. The highest number was assigned to that response indicating the highest level of experience. In the case of items comparing prior pregnancies and prior labor and delivery (Items 7 and 8 ). dual criteria were used. Prior experiences were compared to both positiveness and similarity with both required for the highest rating. No experience was expected to be preferable in relation to stress to any negative experience. And positiveness of present experience was given priority over similarity to past experience.

support system Checklist. This study requires an instrument to measure support systems that is simple and direct, tapping the mother's perception of the value of that support to her. Zimmerman (1980) adapted such an instrument 
from the Bronfenbrenner et al. (1977) Interview of Family Stresses and Supports. Zimmerman (1977) reported this to be a suitable measure of the perceived helpfulness of a wide range of people and services that might make up a support system for both parents of handicapped and non-handicapped children. ( See Appendix C)

The 18 item checklist has two components. The first asks parents to rate each source of support as to its helpfulness to them as a parent, and also to indicate those sources of support that are not available or not used by them. Individual items are rated from (1) Not at all helpful to (7) Extremely helpful. Items were scored in accordance with with number circled. The checklist yields a total support score which is the sum of the individual ratings.

In the second component of the scale, parents are asked to code the kind of support each provides. Four categories of support (emotional, advice-feedback, tangible, and general services) are used. This part of the scale could not be used in the data analysis. Examination of the raw data quickly showed that the social support codes were not mutually exclusive categories. Many of the subjects indicated more than one support code per source, in spite of instructions to the contrary. Thus, the use of these codes was psychometrically untenable and the social support code variables were dropped from the analysis.

In addition, some of the potential sources of support 
which had been thought to be commonly available to new mothers were not used by many of the subjects. For example. only $5 \%$ of the subjects had available psychologists. Many researchers have criticized measures focusing on the quantity of support provided as opposed to the quality. Realizing that retaining measures of these sources of support that were available to only a few of the subjects would have the effect of once again giving quantity of support too much weight in the analysis, any variable with more than 10 missing values was dropped from subsequent analysis. Therefore, 7 variables remained as measures of the quality of social support and were used in the data analysis.

After eliminating all variables with more than 10 missing values, there still remined 39 instances of a missing source of support (out of a possible 707 opportunities). However, listwise deletion of these individuals cases would result in only 70 cases entering into the analyses rather than 101. Therefore, in the interest of preserving other important data, the 7 social support variables were recoded with means inserted in place of missing values.

\section{Data Reduction}

The first task in managing the data of the study was to reduce the the large number of independent variables to a more parsimonious collection. The 15 PSI scales and 18 CPI scales were reduced to 2 Domains and 4 Sub-classes, respectively on the basis of test manual protocols. However. 
the remaining variables--stressors, experience, and social support--required special analyses for their reduction. What follows is a description of how these variables were reduced to a smaller number of conceptual variables through factor analysis.

Stressors. In addition to Life stress, a domain score of the PSI. seven stressor scores were derived from selected items of the Background Information questionnaire (Appendix D). Planned pregnancy (item 3); wanted pregnancy (item 4); stress of pregnancy (item 5); stress of labor and delivery (item 12); and method of delivery (1tem 11); complications of labor and delivery (item 12): and method of delivery (item 13). How each of these variables were defined numericallly was described in the previous section. The intercorrelations of these stressor variables is shown in Appendix G.

The $8 \times 8$ correlation matrix was subjected to a princlple components analysis and a scree test conducted by plotting the eigenvalues of the matrix aqainst their serial order of magnitude (Cattell, 1967). The scree suggested that a two factor solution would be appropriate for a parsimonious, yet complete interpretation of the intercorrelations. About half (actually 49\%) the total variance of the variables was accounted for by the two components. The conponents were rotated to simple structure according to the Varimax criterion. The resulting factor loadings are shown in Table l. As can be seen in the table. 
Table 1

Stressor Variables

Var1max Rotated Factor Loadings

\begin{tabular}{lcc} 
Variables & Factor I & Factor II \\
\hline Life Stressors & & \\
Planned Pregnancy & .71 \\
Wanted Pregnancy & .79 \\
Stress of Pregnancy & .41 & .58 \\
Complication Pregnancy & .31 & .56 \\
Stress of L\&D & .70 & \\
Complications L\&D & .86 & \\
Method of Delivery & .63 & \\
\hline
\end{tabular}

Note. Loadings less than .30 are omitted 
Life stress (the PSI scale) not load highly on either factor. Apparently, the type of stress measured by this scale bears little relationship to that assessed on the Background Information questionnaire. Therefore, Life stress will remain intact as an independent variable in the study.

The high loading items of Factor I included stress of labor and delivery, complications of labor and delivery, and method of delivery. This factor was named "Labor and delivery stressors." Unlike Factor I, the high loading items of Factor II included only items linked to pregnancy. These included planned pregnancy, wanted pregnancy, stress of pregnancy, and complications of pregnancy. This factor was named "pregnancy stressors." Thus, on the basis of this analysis, three types of variables were identified: Lffe stress, labor and delivery stressors, and pregnancy stressors. By summing the standard scores of high loading items of each factor, single indices for the latter two variables were generated.

Experience variables. Eight of the nine experience variables described earlier were included in the second factor analysis. Like the stressors, most of these data were taken from the Background Information questionnaire. However, the first three variables, age, mother's education, and father's education were taken from the header and two items of the PSI. Other experience variables included: Lamaze training (item 9), at least two years of employment (item 17), occupational training of at least two years (item 18). 
prior pregnancy comparison (item 7), and prior labor and delivery comparison (item 8). The numerical scoring for all these variables has already been described. Number of other children was considered a varlable of interest in its own right and was not included in this analysis. Intercorrelations among the experience variables are shown in Appendix I.

As with the previous analysis of the stressor variables, this $8 \times 8$ correlation matrix was subjected to a principle components analysis. Once again the scree test suggested the appropriateness of two factors, and such a solution accounted for $51 \%$ of the total variance. The first two principle components were rotated to simple structure according to the Varimax criterion. Factor loadings are shown in Table 2. As can be seen in the table, Factor I included age, mother's education, father's education. Lamaze training, employment of at least two years, and occupational training of at least two years. Factor II included the remaining two variables--prior pregnancy comparison and prior labor and delivery comparison. Factor I was subsequently named "General preparatory experiences." In order to create a single index for each dimension, all the items were standardized and the high loading items of each factor summed.

Social Support Variables. As indicated earlier, seven of the original 18 support measures had sufficient numbers of respondents to be included in the data reduction. The first 
Table 2

Experience Variables

Varimax Rotated Factor Loading s

Variables

Factor I

Factor II

\begin{tabular}{|c|c|c|}
\hline Ag̣e & .57 & \\
\hline Mother's Education & .81 & \\
\hline Father's Education & .71 & \\
\hline Lamaze Training & .57 & \\
\hline Employed 2 Yrs & .63 & \\
\hline Trained 2 Yrs & .61 & \\
\hline Prior Pregnancy & & .80 \\
\hline Frior L\&D & & .80 \\
\hline
\end{tabular}

Note. Loadings less than .30 are omitted. 
four of these measures include support from one's own spouse (item 1), Mother (item 2), Friends (item 5), and Medical Doctor (1tem 18). The remaining three items included support from Written material (item 6), Spouse's Family (item 16), and Other Parents (item 14). These measures were coded on Likert scales that ranged from one to seven (See Appendix C). The intercorrelations among these variables are shown in Appendix $\mathrm{H}$.

Not unlike the previous data reductions, the correlation matrix (in this instance a $7 x$ ) was subjected to a principle components analysis and a scree test condected. The results of this test suggested that two factors should be extracted. The first two principle components were rotated to simple structure according to the Varimax criterion and the results are shown in Table 3 . About $51 \%$ of the total variance of the seven variables is accounted for by the two factors.

Factor I includes suppport from Friends, Written materials and other parents; Factor II, support from one's own Spouse, Mother, Medical doctor and other own family. It would seem, then, that Factor II represents Primary support--that received from the most important individuals in the subjects life during the time period studied. Factor I, on the other hand, represents sources of more distant support, or Secondary support. Each of these dimensions was scored by summing the items of the high loading items. When scaled in this fashion. Primary Support (i.e., Factor II) had 
Table 3

Social Support Variables

Varimaz Rotated Factor Loadinas

\begin{tabular}{lcc} 
Variables & Factor I & Factor II \\
\hline Friends & .70 & \\
Written Material & .64 & \\
Other Parents & .84 & \\
Spouse & & .32 \\
My Mother & .87 \\
Other Own Family & .51 \\
Private Doctor & .69 \\
\hline
\end{tabular}

Note. Loadinas less than .30 are omitted. 
an alpha reliability of .61; Secondary Support (i.e.. Factor I). .63 .

\section{Plan of Aralysis}

The analysis of the study will be guided by three hypotheses.

Hypothesis I. Stressors will predict stress as measured by the PSI at six to eight weeks post partum. Stressors include life stress, unplanned pregnancy, unwanted pregnancy. rated stress of pregnancy, rated stress of labor and delivery, complications of pregnancy, complications of labor and delivery and caesarean section. The plan is to first examine the correlations of these variables with Total stress and Parenting Domain Stress to understand the simple effects. Then, to improve the prediction of stress, these stressor variables will be combined in a multiple regression equation with Total stress as the dependent variable.

Hypothesis II. Total Personality, Primary Social Support, Secondary Social Support, General Experience, and Prior Specific Experiences will all be inversely related to stress. To test this hypothesis, correlations will be obtained between each of these variables and Total and Parent Domain stress.

Hypothesis III. Stressful events such as unplanned and unwanted pregnancy, medical complications of pregnancy or labor and delivery, higher levels of stress in pregnancy or labor and delivery and child domain stress will be related to 
levels of parenting stress at six to eight weeks post partem when mediating variables are held constant. A multiple regression equation will be constructed so that the mediating variables of Total Personality, Primary Support, Secondary Support, General Experience, and Prior Specific Experience will be entered first. After their effects are removed, the stressor variables will be entered in the reduced form of Pregnancy Stressors and Labor and Delivery Stressors. Total Stress, as measured by the PSI, will be the dependent variable. In this manner, the effects of stressors will be tested after the mediating variables have been controlled.

A second equation will be constructed identically. except that Parent Domain stress will be the dependent variable and Child Domain Stress will also be one of the stressor variables. 
To identify the factors that predict stress in mothers of infants six to eight weeks of age, three general hypotheses were proposed at the end of Chapter II. After a descriptive summary of the data, the present chapter will report the results related to each hypothesis. For each hypothesis, the simple effects of specific variables will first be examined, then the simple effects of the variable groups which were formed by data reduction techniques. Last. the effects of the groups of variables in combination will be examined for their additive and interactive effects.

\section{Descriptive Summary}

A descriptive summary of the CPI scores is shown in Appendix $K$. In all instances, the means for the present sample fall close to those in Gough's (1975) normative sample.

The summary of the PSI scores is shown in Appendix I. Although the standard deviations are extremely close to those listed by Abidin (1983), the subscale and overall means are sligntly higher than those of his normative sample. It is possible that the elevation of these scores is because mothers of six to elght week old infants are likely to be more stressed than the mothers in Abidin's normative sample who had children of varying ages. That is, one expects newer 
mothers to be more stressed, and that is precisely the reason that age was chosen for this study.

Social support data are shown by frequencies in Appendix M. As stated earlier, thoses variables with more than 10 instances of "0" frequency were not used in subsequent analysis. The least available sources of support were psychologist, school programs, social services and other children, in that order. These sources of support were available to less than half the respondents.

The Stressor and Experience variables are summarized by frequencies in Appendix $\mathrm{N}$ and Appendix 0 respectively. All categories of response include at least one respondent. However, they are not represented equally. For example, planned pregnancy is much more common than unplanned pregnancy and having a large number of other children is uncommon.

\section{Hypothesis I}

Stressors will predict stress as measured by the PSI at six to eight weeks post partum. Stressors include life stress, unplanned pregnancy, unwanted pregnancy, rated stress of pregnancy, rated stress of labor and delivery, complications of pregnancy, complications of labor and delivery, and caesarean section.

First, correlations of each of these variables with Total Stress and Parenting Domain Stress were generated (See Table 4). Among the stressors, unwanted pregnancy was most 
Table 4

Correlation of Stressor Variables with Stress

Total

Stress

\begin{tabular}{lll}
\hline Life Stress & .08 & .07 \\
Preçnancy Stressors & $.38 \star \star$ & $.44 \star \star$ \\
Unplanned Preqnancy & $.32 \star \star$ & $.36 \star \star$ \\
Unwanted Preonancy & $.35 \star \star$ & $.37 \star \star$ \\
Stress of Prequancy & $.30 \star \star$ & $.33 \star \star$ \\
Complications Pregnancy & .05 & .13 \\
L\&D Stressors & .01 & .06 \\
Stress of L\&D & .08 & .14 \\
Complications L\&D & .05 & .01 \\
Method of Delivery & .00 & .04 \\
\hline
\end{tabular}

Note. $t \star p<.01$.
Parenting Domain 
related to both Total stress $(r=.35 ; p(.001)$, and Parent Domain Stress $(r=.37 ; p<.001)$. Unplanned pregnancy was also significantly related to Total Stress $(r)=.32 ; p<$ $.001)$, and Parent Domain Stress $(r=.36 ; p(.001)$. Unplanned and unwanted pregnancy, as might be expected, were highly intercorrelated $(r=.56)$.

Neither complications of pregnancy nor complications of labor and delivery were significantly related to Total Stress. However, the rated stress of pregnancy was moderately correlated with Total stress $(r=.30 ; p<.001)$ and Parenting Domain Stress $(r=.33 ; p<.001)$. Method of delivery was not related to either dependent variable.

Pregnancy Stressors, a variable careated through factor analysis from a linear combination of unplanned and unwanted pregnancy and rated stress of pregnancy, was moderately correlated with Total stress $(r=.38)$ and even more strongly related to stress from the Parenting Domain $(r=.44)$. Labor and Delivery stressors, which included complications and rated stress of labor and delivery, was not significantly related to Total stress $(r=.01)$. None of the Factor II stressor variables were significantly related to stress. Thus, hypothesis I was supported with respect to unplanned pregnancy, unwanted pregnancy, rated stress or pregnancy and the Pregnancy sub-class. It was not supported by findings on complications of preqnancy or labor and delivery, nor the predicted effect of caesarean section. 
To Improve the prediction of Total stress and Parent Domain stress, the stressor variables were combined in a regression equation. Table 5 shows the results of regression analysis. Stress can be predicted moderately well from a linear combination of stressors $(R=.50)$. Wanted pregnancy. stress of pregnancy, and planned pregnancy, in that order. accounted for about $23 \%$ of the explained variance.

Hypothesis II.

Total Fersonality, Experience (General Experience, and Specific Prior Experience), and Social Support (Primary Social Support and Secondary Social support), will be inversely related to Total stress and Parent Domain stress. To test this, correlations were obtained between each of these variables and the dependent variables of Total stress and Parent Domain Stress.

Effects of Personality. Table 6 shows the correlations of the the CPI sub-class scales with Total and Parent Domain stress. The correlations ranged from-.30, for the sub-class Intellectual and Interest Modes with Parent Domain to -.53 for the Intrapersonal Values sub-class with the Parent Domain. Total personality had the strongest relationship with stress of any of the classes of variables. The correlation between the Parent Domain and the Total stress was -.57 ( $p<$ $.001)$. The relationship between Total stress score and the Total personality score was $-.53(p<.001)$.

Effects of Experience. The simple effects of individual 
Table 5

Reqression of the Stressor Variables on Total Stress

\begin{tabular}{lccc}
\hline Variable & $R$ & $R 2$ & $\begin{array}{c}R 2 \\
\text { Chanqe }\end{array}$ \\
\hline Wanted Preqnancy & .39 & .15 & $.15 \star \star$ \\
Stress of Preqnancy & .45 & .20 & $.05 \star$ \\
Planned Preqnancy & .48 & .23 & .02 \\
Complications Preqnancy & .49 & .24 & .01 \\
Life Stress & .49 & .24 & .00 \\
Complications L\&D & .49 & .24 & .00 \\
Method of Delivery & .50 & .25 & .00 \\
Stress of L\&D & .50 & .25 & .00 \\
\hline
\end{tabular}

Note. $\star \star 0<.01 . \quad \star p<.05$.

Note. $\mathrm{N}=101$. 
Table 6

Correlations of CPI Sub-clagses with stress

Total

stress
Parent

Domain

Polse, Ascendency,

Interpersonal Adequacy I

$-.42 \star \star$

$-.47 \star \star$

Socialization.

Responsibility, Intra-

Personal Values.

Character

II

$-.50 \star \star \quad-.53 \star t$

Achievement Potential

I I I

$-.50 * t \quad-.52 \star t$

Intellectual and

Interest Modes

IV

$-.31 \star \star ⿻$

$-.30 \star \star t$

Note. $t+p<.01$. 
varlables were examined first. Some of the individual experience variables were moderately related to Total stress and to Parenting Domain stress. Table 7 shows these relationships. The strongest relationship was between Prior Pregnancy Comparison (shown in table as Prior Pregnancy) and the Total stress $(r=-.31 ; p<.001)$. Also significant was Prior Labor and Delivery Comparison and Total stress $(\boldsymbol{r}=$ $-.23 ; \mathrm{p}<.05\rangle$. The sum of these two variables, which were combined through factor analysis, to form the specific Prior Experience, was correlated with Total Stress $(r=-.38)$, and Parent Domain Stress $(r=-.44)$.

Only two of the variables in the General Preparatory Experience sub-class were related significantly when correlated with Total stress. They were mother's education ( $r$ $=-.29)$ and father's education $(r=-.26)$. Also there was little relationship between Total stress and age $(r=-.05)$, Lamaze training $(r=-.07)$, length of employment $(r=-.13)$ and length of training $(x=-.09)$. A similar set of correlations emerged when these same variables were correlated with Parent Domain stress. The sub-class of General Preparatory Experiences was significantly related to Total Stress $(r=-.22)$, and to Parent Domain $(r=.20)$.

Effect of Social Support. All of the individual social support variables were negatively related to stress. Table 8 depicts the correlations of the individual social support variables with Total stress and Parenting Domain stress. 


\section{Table 7}

Correlation of Experience Variables with Stress

\begin{tabular}{lcc}
\hline & $\begin{array}{c}\text { Total } \\
\text { Stress }\end{array}$ & $\begin{array}{c}\text { Parent } \\
\text { Domain }\end{array}$ \\
\hline General Experience & $-.22 \star$ & $-.20 \star$ \\
Age & -.05 & -.04 \\
Mother's Education & $-.29 \star \star$ & $-.28 \star \star$ \\
Father's Education & $-.26 \star$ & $-.28 \star$ \\
Employment 2 Yrs & -.13 & -.07 \\
Training 2 Yrs & -.09 & -.05 \\
Lamaze Training & -.07 & -.09 \\
Other Ch1ldren & $.21 \star$ & .11 \\
Prior Specific Experience & $-.38 \star \star$ & $-.44 \star \star$ \\
Prior Preqnancy & $-.31 \star \star$ & $-.20 \star$ \\
Prior L\&D Comparison & $-.23 \star$ & $-.17 \star$ \\
\hline
\end{tabular}

Note. $\star \star p<.01 . \star t p<.05$. 
Table 8

Correlation of Social Support Variables with Stress

\begin{tabular}{lcc}
\hline & $\begin{array}{c}\text { Total } \\
\text { Stress }\end{array}$ & $\begin{array}{c}\text { Parenting } \\
\text { Domain }\end{array}$ \\
\hline Primary Support & $-.21 \star$ & $-.27 \star \star$ \\
Spouse & $-.25 \star \star$ & $-.33 \star \star$ \\
Mother & -.05 & -.08 \\
Other Own Family & -.10 & -.09 \\
MD & -.15 & $-.20 \star$ \\
Secondary Support & -.10 & $-.19 \star$ \\
Friends & $-.16 \star$ & $-.24 \star \star$ \\
Written Material & -.05 & -.11 \\
Other Parents & -.01 & -.08 \\
\hline
\end{tabular}

Note. $* t p<.01 .+p<.05$. 
Unlike the experience variables, higher magnitude relationships were found with Parent Domain rather than Total Stress.

The quality of support from the spouse was the individual support variable with the strongest relationship to Total stress $(r=-.25)$, and Parent Domain Stress $(r=$ -.33). However, support from mother bore little relationship to either Total Stress. $(r=-.05)$, or to Parent Domain $(r=$ -.08). Support from Private doctor correlated with Total Stress $(r=-.15)$ and (Parent Domain Stress $(r=-.20)$. Support from other own family correlated with Total stress ( $r$ $=-.10)$ and Parent Domain Stress $(r=-.09)$. The four variables just mentioned had previously been combined through factor analysis to form Primary support. Primary support was inversely related to Total Stress $(x=-.21)$ and Parent Domain Stress $(x=-.27)$.

For Secondary Support, the variable with the strongest relationship was support from friends which was related to Total stress $(r=-.16)$ and Parent Domain Stress $(r=-.24)$. Support from written materials and other parents were not significantly related to either dependent variable. Secondary Support was inversely related to Parent Domain $(x=-.19)$, but not significantly related to Total Stress $(x=-.10)$.

Thus, Hypothesis II was supported in that Total Personality, Primary Social Support, Secondary Social Support, General Experience, and Prior Specific Experience 
were all inversely related to stress. Having established that simple effects of stressors, personality, experience and social support are significantly related to stress, their interrelationships and effects in combination will now be considered.

Hypothesis III

Stressful events such as unplanned and unwanted pregnancy, medical complications of pregnancy or labor and delivery, higher levels of stress in pregnancy or labor and delivery and Child Domain stress will be related to levels of stress at six to eight weeks post partem when mediating variables are held constant.

The following independent variables are believed to mediate stress: Total Personality, Primary Support, Secondary Support, General Experience, and Prior Specific Experience. A multiple regression equation was constructed so that the mediating variables were entered first. After their effects were removed, the stressor varlables were entered in the reduced form (recall the data reduction described earlier). In this manner, Total Stress was predicted from a combination of stressor and mediating variables.

The results, shown in Table 9, indicate that Total Personality was the strongest mediating variable and was entered first (R2 = .28). Prior Experience was entered second. $\left(R^{2}\right.$ change $=.04 ; p(.05)$. Other mediating variables did not account for significant additional variance. 
Table 9

Multiple Regression Analysis of Total Stress with Five Moderator Variables Controlled

\begin{tabular}{|c|c|c|c|c|}
\hline Varlable & $R$ & $R^{2}$ & $\begin{array}{c}\mathrm{R}^{2} \\
\text { Change }\end{array}$ & $\bar{r}$ \\
\hline Total Personality & .53 & .28 & $.28 \star \star$ & -.53 \\
\hline Prior Experience & .57 & .32 & $.04 \star$ & -.33 \\
\hline Primary support & .59 & .35 & .02 & -.21 \\
\hline General Experience & .59 & .35 & .01 & -.22 \\
\hline Secondary Support & .59 & .35 & .01 & -.10 \\
\hline Pregnancy stressors & .63 & .40 & $.05+t$ & .38 \\
\hline L\&D Stressors & .63 & .40 & .00 & .01 \\
\hline
\end{tabular}

Note. $* \star \mathrm{p}<.01$.

Note. Overall $F=8.8$.

Note. All tables represent 101 cases. 
Pregnancy Stressors entered first after the mediating variables were controlled and accounted for significantly more variance $(R 2$ change $=.05 ; p=(.01)$. The combination of these variables explained $40 \%$ of the variance of Total stress.

A second equation was constructed in which Parent Domain Stress was the dependent variable and Child Domain Stress was one of the Stressor variables. The results are shown in Table 10. Total Personality entered first, as before. Primary Support entered second, contributing significant additional variance (R2 change $=.04 ; p<.01)$. General Experience, Prior Experience and Secondary Support were not significant contributers of additional explained variance. of the stressors, Child Domain made the largest contribution ( $R 2$ change $=19 ; \mathrm{p}(.01)$. Pregnancy Stressors was also contributed additional variance ( $R 2$ change $=.06: p<.01)$. Labor and Delivery Stressors did not add to the prediction significantly. The combination of all these variables explained $66 \%$ of the variance of Parent Domain Stress.

The mediating effect of the variables was further examined by comparing the above regression analyses to one in which Stress of Pregnancy and Stress of Labor and Delivery were entered first. Then the hypothesized mediating variables were entered. Table 11 shows the results of this analysis. Results show that parenting Stress may be predicted with significant accuracy from a linear combination of the 
Table 10

Multiple Reơression Analysis of Parent Domain Stress With Five Moderator Variables Controlled

\begin{tabular}{lcccr}
\hline Variable & $R$ & $R^{2}$ & $\begin{array}{c}R^{2} \\
\text { Change }\end{array}$ & $\begin{array}{r}\text { Simple } \\
r\end{array}$ \\
\hline Total Personal1ty & .57 & .32 & $.32 \star \star$ & -.57 \\
Primary Support & .61 & .37 & $.04 \star \star$ & -.27 \\
General Experience & .62 & .39 & .02 & -.22 \\
Prior Experiencece & .63 & .39 & .01 & -.22 \\
Secondary Support & .63 & .40 & .00 & -.19 \\
Child Domain & .77 & .60 & $.19 \star \star$ & .62 \\
Preqnancy Stressors & .81 & .65 & $.06 \star \star$ & .44 \\
L\&D Stressors & .81 & .66 & .01 & .06 \\
D & & & & \\
\hline
\end{tabular}

Note. $\star \star x<.01 \quad \star p<.05$. overa11 F. 22.6 . 
Table 11

Multiple Reqression Analysis of Total Stress

With Two Stressor Variables Controlled

\begin{tabular}{lcccc}
\hline Variable & $R$ & $R 2$ & $\begin{array}{c}\text { R2 } \\
\text { Change }\end{array}$ & $\begin{array}{c}\text { Simple } \\
r\end{array}$ \\
\hline Fregnancy Stressors & .38 & .15 & $.15 \star \star$ & .38 \\
L\&D Stressors & .38 & .15 & .00 & .01 \\
Personality & .58 & .34 & $.20 \star \star$ & -.53 \\
Prior Experience & .61 & .37 & $.03 \star$ & -.33 \\
Primary Support & .62 & .39 & .02 & -.21 \\
General Experience & .63 & .40 & .01 & -.22 \\
Secondary Support & .63 & .40 & .00 & -.10 \\
& & & & \\
\hline
\end{tabular}

Note. $\star \star p<.01 . \star p<.05$.

Note. Overall $\mathrm{F}=.8$. 
stressor and mediating variables $(R=.63)$. However, only three variables, when entered in this fashion, contribute significant explanation of variance: the stress of pregnancy. when entered first, (R2 change $=.15 ; \mathrm{p}(.001)$; total personality, when entered third, $(R 2$ change $=.20 ; p(.001)$; and prior experience, when entered fourth $(R 2$ change $=.03$; $p$ $(.05)$.

A similar equation was constructed with Parenting Domain stress as the dependent variable and Child Domain included as an independent variable. This equation yielded some difference in results (See Table 12). Child Domain entered first, and Pregnancy stressors Delivery entered second, both at significant levels $(p<.01)$. However, Labor and Delivery stressors still did not add significantly after the other variables were controlled. Three mediating variables entered at statistically significant levels when stressors were controlled: Personality ( $R 2$ change $=.11 ; \mathrm{p}(.001) ;$ Secondary Support (R2 change $=.03 ; \mathrm{p}<.01$.$) ; and General Experience$ $(\mathrm{R} 2$ change $=.02 ; \mathrm{p}(.05)$. The combination of these variables yielded a high multiple correlation $(R=.81 ; F=22.6$; $p(.001)$.

\section{Other Interesting Findings}

It is interesting to note that neither complications of pregnancy nor complications of labor and delivery were not related to parenting stress. However, such complications were related to the rated stress of pregnancy $(r=.27)$ and rated 
Table 12

Multiple Regression Analysis of Parent Domain Stress With Three Stressor Variables Controlled

\begin{tabular}{lcccc}
\hline Variable & $R$ & $R 2$ & $\begin{array}{l}\text { R2 } \\
\text { Change }\end{array}$ & $\begin{array}{c}\text { Simple } \\
r\end{array}$ \\
\hline Child Domain & .62 & .39 & $.39 \star \star$ & .62 \\
Pregnancy Stressors & .70 & .49 & $.10 \star \star$ & .44 \\
L\&D Stressors & .70 & .50 & .01 & .06 \\
Total Personality & .78 & .60 & $.11 \star \star$ & -.57 \\
Secondary Support & .79 & .63 & $.03 \star \star$ & -.19 \\
General Experience & .80 & .65 & $.02 \star$ & -.20 \\
Prior Experience & .81 & .66 & .01 & -.22 \\
Primary Support & .81 & .66 & .01 & -.27 \\
\hline
\end{tabular}

Note. $\star \star p<.01 \quad \star p<.05$.

Note. Overall $F=22.6$. 
stress of labor and delivery $r=.26$ ). See Appendix $G$. In fact, the complications of pregnancy, labor and delivery were more highly related to the rated stress of pregnancy than any of the other variables. Further, the rated stress of pregnancy was correlated with Total stress $(x=.30 ; p<$ $.001)$ and Parenting Domain Stress $(r=.33 ; p<.001)$. Thus, these early untoward experiences seem to influence the perception of that experience itself, but they do not influence parenting stress at six to eight weeks post partum. The only variable in the study that deviated directionally from its predicted relationship to stress was number of other children. Since having children provided prior experience, it was expected that number of other children would be protective and would be negatively correlated with stress. However, it proved to be positively correlated with Total stress $(r=.21)$ instead. A possible explanation for this finding appeared when a regression analysis was done with Parent Domain Stress as the dependent variable and the effects of Child Domain Stress removed first. With the Child Domain variance controlled, the partial correlation of number of other children was $(x=-.18)$. Not only is that relationship in the predicted inverse direction. but the magnitude approaches that of the original positive relationship and it is statistically significant (p (.05). Thus it appears the number of other children is a confounded variable. It may be true that number of other children 
provided some protection, but its relationship with Child Domain Stress suggests that a number of children may have other stressful elements associated with it. Thus, the net effect appears to be a negative one.

Finally, it was of interest to determine how much prediction of stress could be made from personality when other variables were controlled. Table 13 shows the summary of this analysis. In this equation, the effect of Personality, with the effects of Stressor and Mediator variables controlled, still retains a partial correlation ( $r$ $=-.42, p(.001)$. It is statistically significant and adds an $R 2$ change of .13 even when entered last. 
Table 13

Multiple Regression Analysis of Personality on Total Stress With Stressors and Moderator Variables Controlled

\begin{tabular}{lcccc}
\hline Variable & $\mathrm{R}$ & $\mathrm{R} 2$ & $\begin{array}{c}\mathrm{R} 2 \\
\text { Chanqe }\end{array}$ & $\begin{array}{c}\text { Simple } \\
\text { r }\end{array}$ \\
\hline Pregnancy Stressors & .38 & .15 & $.15 \star \star$ & .38 \\
Life Stress & .40 & .16 & .01 & .08 \\
L\&D Stressors & .40 & .16 & .00 & .01 \\
Prior Experience & .46 & .21 & $.05 \star \star$ & -.33 \\
Primary Support & .50 & .25 & $.04 \star$ & -.21 \\
General Experience & .52 & .27 & .02 & -.22 \\
Secondary Support & .52 & .27 & .00 & -.10 \\
Personality & & & $.13 \star \star$ & -.53 \\
\hline
\end{tabular}

Note $\star \star p<.01 . \star 0<.05$. 
CHAPTER IV

CONCLUSION

This investigation examined the factors that predict parenting stress as measured at six to eight weeks post partum. More specifically, the research questions were: (a) To what extent are stressors that are experienced prior to the birth related to stress postpartum. (b) What is the relationship between personality, experience, social support and stress. (a) What is the relationship of stressful events to stress when the moderator variables are controlled.

Through the review of literature, a general model of stress was proposed. The model predicted that stressful events, even though they may have occured as much as a year earlier, are related to the later experience of stress. The model further sugrested that these stressful events do not by themselves account for the experience of stress. The effects of these stressful events may be mediated by several resources that may be available to individuals. These resources include: ego strengths of personality; presence of helpful social support systems: and memory of past successful experiences that were preparatory either by general or specific similarity. The findings of this study support this general model. Although the weight of statistical significance was not present for the effects of a number of 
individual variables, the overall pattern of relationships bore striking agreement to the proposed model. The findings of the study will now be summarized and discussed.

stressors

To what extent are pre-birth stressors related to early parenting stress? Although the stressors occurred six weeks to one year prior to the measurement of parenting stress, three of these variables were significantly related to parenting stress post partum. Unwanted pregnancy was shown to be a potent contributer to stress. Although McGrath (1970) did not specificaliy discuss childbearing stress. this is entirely consistent with his observation that assimilation of circumstances is more difficult when the onset is felt to be beyond control and unpleasantness is also anticipated.

The rated stress of pregnancy is significantly related to Total Stress and Parent Domain Stress. Rated stress is also related to complications of pregnancy. However. complications of pregnancy is not signficantly related to parenting stress. Thus it is likely that the perception of stresstulness rather than physical complications is more predictive of later stress.

Unplanned pregnancy is related to parenting stress. However, unplanned pregnancy is moderately correlated with unwanted pregnancy and when the effects of unwanted pregnancy have been removed, the partial correlation of unplanned pregnancy with Total stress drops to non-significance. It 
seems logical to assume that unplanned pregnancy is a necessary. but not sufficient condition for unwanted pregnancy. In McGrath's (1979) terms, the unplanned pregnancy is "unanticipated", but the unwanted pregnancy includes the "continued anticipation of unpleasantness" with no avenue of escape. Thus, unwanted pregnancy is probably a variable of much greater import than unplanned pregnancy, although this cannot be known from these findings alone.

Mediating Variables

As mentioned earlier, the model of stress proposed in the review of the literature suggests that the effect of stressful events may be mediated by certain factors. The ego strength of personality, helpful social support systems and past similar and positive experiences were proposed as mediators. The effects of these mediators as found in the present study will now be discussed.

Experience. Experience variables bore a significant inverse relationship to parenting stress. An important finding of this study is that the strongest relationships are seen between the comparison to prior pregnancies and the Total Stress scores and comparison with prior labor and delivery experiences and stress. Since these two variables represent specific prior experience, they are supportive of the Dohrenwend and Dohrenwend (1978) contention that the person's prior history of dealing with stressors is very important and leads to habituation such that later 
experiencing of these events results in lower levels of emotionality. McGrath (1970) adds that specific prior experience with the task, the stressor and or the situation, attenuated the effect of stress. Training is a blessing with respect to alleviation of stressful effects. Further, the measurement of experience in the present study also included a qualitative assessment of whether prior experiences were positive or negative. It was clear from the findings that this was a very important aspect of experience. Positive experiences were indeed related to lower levels of stress and no prior experience seemed preferable to negative experiences in relation to stress. Thus, it was also possible to support McGrath's impression that fallure breeds failure and the experience of fallure on a task is stressful in itself. McGrath's conclusion that if a prior experience is negative it will increase stress and $1 f$ prior experience is successful or otherwise leads to learning, mastery or adaptation, stress will be decreased was supported by this finding.

Two other experience variables were inversely related to parenting stress. They were mother's education and father's education. However, both mother's education and father's education were also related to personality. If the effects of personality on stress were removed, the partial correlations of both mother's and father's education were insignificant.

other experience variables, though negatively correlated with stress, did not reach statistically significant levels. 
Lamaze training was not significantly related to parenting stress or to the rated stress of labor and delivery as one might expect it to be. Since Lamaze is a form of specific training, which through its use of simulations and rehearsal techniques might even be described as a vicarious experience, this is a surprising finding. Lamaze training is a practical and popular form of intervention. Therefore, it is disappointing that a protective effect on stressfulness of the childbirth experience was not shown in this study. Further research is needed to clarify the meaning of this finding.

Social Support. The presence of social support was inversely related to parenting stress. Although all of the support variables that were ultimately included in the study were neqatively correlated with stress, only effects of support from the spouse, private doctor, friends and written materials were statistically significant. As suggested by the Lieberman study (1980), the strongest effect was produced by the quality of support provided by the spouse. According to Lieberman, for those women whose husbands do not provide needed resources, there was no evidence that other resources could substitute.

Personality. Personality had the strongest mediating effect of stress of any of the variables. Its relationship was so robust that even when forced to enter the regression equation last, it still exerted a statistically significant 
influence ( $p(.001)$. This finding is supportive of the previous research of Sarason (1980), Lazarus (1982), and Janis, (1982). Sarason (1980) noted that personality characteristics and dispositions to appraise tasks in particular ways play a role in a person's response to a call for action. The findings also support the view of Lazarus (1982), that stressful experiences do not take their toll from a passive individual, but from one who is imbuing stressful circumstances with personal meaning and struggling to control and master these circumstances. Because these mediating psychological processes are important determinants of the stress experience, it is inevitable that situations will be encountered in which there is little or no relationship between the severity of the adjustment demands implnging on the individual and the adaptational consequences of these demands. Thus, summarizes Lazarus, our efforts to understand the impact of stress will be heavily dependent on the success with which we are able to conceptualize these mediating psychological processes. Present findings also support Depue (1979), who noted that psychological characteristics operate directly on the appraisal process and predispose an individual to perceive a particular class of events as threatening to personal security. Psychological characteristics affect more general cognitive schemas, such as might be termed self-efficacy. Janis (1982) noted that the readiness to become jittery and to perceive danger is related 
to a number of personality variables, notably low ego strength and low self confidence.

Mediation of Stress

Are stressful events related to stress when mediating variables are controlled? Results of regression analysis showed that with such variables controlled, the stressors of Pregnancy are related to Total Stress. When Parent Domain was the dependent variable, all of the stressors, (i.e., Child Domain, Stressors of Pregnancy and Labor and Delivery Stressors) were significant predictors. This finding indicates that untoward experiences exert their effects in addition to the influence of mediating factors of personality, experience or social support, at least over the period of time examined in this study.

Complications of pregnancy, complications of labor and delivery and method of delivery were not related to parenting stress when only the simple effects were considered. They are however, related to the rated stress of those experiences. Therefore, the finding does not support to the findings of Trowell (1982) that mothers who had difficult labor and delivery experiences had more doubts about their ability to care for their babies and found the practical tasks of motherhood more overwhelming than a comparative group of mothers with normal labor and delivery.

The present findings also are not consistent with those of Affonso (1977), or Lipson and Tilden (1980). It is also 
supportive of the findings of Trowell (1982) who found that mothers who were delivered by Cesearean section had more doubts about their capacity to care for their babies, were more depressed and felt their babies did not become a person until later, had more difficulty adjusting to the baby and found the responsibilities of parenthood more difficult to accept.

The findings related to the impact of Child Domain as a stressor when the moderating variables are controlled. support the views of Bell (1968, 1974, 1977) and Thomas, Chess and Birch (1968) on the potential of the child's characteristics to serve as a stressor. Differences in a child's level of adaptability, acceptability, demandingness, mood and hyperactivity influence the stress experienced by the mother. Bell (1977) contends that if the temperment or timing of the child's characteristics does not fit the parent's, adjustments to the child are more difficult. The parent may begin to respond to the child with strategies designed to reduce her own stress, rather that reflecting sensitivity to the child's needs.

\section{Implications of the Study}

The findings of this study are consistent with theories of stress discussed in Chapter I. In fact, all the variables in the study except one (number of other children) were correlated with stress in the predicted direction. In addition to being consistent with existing theory, the 
findings may contribute another insight. At least with respect to parenting stress, personality, prior experience and support are mediating factors. Further, personality is the most effective of these. Perhaps previous research that focused only on support and did not measure personality missed an important opportunity. Such research may have lead to an overestimation of social support in relation to other factors.

Howver, the relationship among personality, support and stress may depend, in part, on the level of stress involved. As Wilcox (1979) pointed out, social support may have relatively little effect under conditions of minimal stress. But as stresses accumulate, the buffering effect of social support becomes more evident. Since the present study measured stress that is arqueably minimal, that may be true here.

A psychometric implication of this study is related to the use of the PSI as a dependent measure of the effects of stressors. In the present study, the Parent Domain was a more sensitive indicator of the effects of stressors as well as the effects of mediating factors. This is logical in view of the intended purpose of the Parent Domain versus the Total Score which, also includes the Child Domain. That is, the Parent Domain measures the mother's ratings of her depression, sense of competence, health, and social isolation which would likely be directly influenced by stressful 
events. The Child Domain, on the other hand, measures distractibility, mood, demandingness and adaptability of the child. The mother's ratings of these are likely to be less influenced by events stressful to her.

There are several clinical implications of this study. Any human phenomenon that can be predicted with reasonable accuracy can be potentially influenced. Although this study does not explore predictions over time or efficacy of treatment. It does suggest interventions that may be helpful. Perhaps mothers at risk for stressful parenthood may be identified earlier. The period of pregnancy may be used as a time to bolster those assets that mediate stress. Pregnant women may be counseled to keep in touch with sources of support, take time to visit friends, seek appropriate written materials and find a physician with whom rapport is likely.

Promoting healthy personality development is both a short term and a long term goal of therapeutic interventions. Years of therapeutic experience have shown the value of beainning this with children and preventing problems before they occur. However, the psychological openness that is characteristic of pregnancy offers another good opportunity to promote healthy personality development. In fact, Caplan (1974) suggested that pregnancy was one of the most opportune times in an individual's life to effect personality changes. The strenath of effect of personality in the present study suggests that the effectiveness of preventive interventions 
administered during pregnancy with the goal of promoting healthy personality might be profitably explored.

The child's characteristics were also shown to have a stong effect on the mother's stress. The strength of this relationship, as with personality, attracts the clinical eye to possible intervention. Although it is not likely the child's characteristics themselves can be altered, it may be possible to alter the mother's perception of them. If mother can be educated as to the typical behavior of infants and normal variations in such attributes as crying and infant temperment, perhaps those characteristics would be viewed as less stressful.

An important finding of this study was the potential value of prior positive experience. Perhaps clinicians should provide debriefing times after chlldbirth experiences. Since these experiences become "prior experience" for the next pregnancy, It may be possible to render them more positive. Clarifying misconceptions, allowing ventilation of feelings and providing support all are potentially helpful. It is possible that such intervention would result in better resolution of the experience.

Perhaps an obvious clinical implication is that written materials should be readily available prenatally and post partum. Written materials may be so obvious an intervention that it is undervalued. In fact, one of the subjects in the present study included a letter with her materials expressing 
her views on the deplorable lack of available, suitable literature.

Summary

Stress in mothers of young infants can be predicted with significant accuracy by combining several factors. These factors include: the stressful events in the prenatal pertod, characteristics of the child, personality of the mother, prior experience and social support. Previous research has shown that circumstances are more difficult when events are unanticipated, uncontrolled, expected to be unpleasant or when the person is already stressed by other matters. When preqnancy is unwanted, unplanned or if the pregnancy is accompanied by complications or otherwise is unpleasant; if the child's characteristics are disagreeable or out of synchrony with the mother's; if other life events cause coexistant stress, then the effects are evident in the stress mothers experience in parenting at six to eight weeks post partum.

The mother's personality, prior experience and social support may mediate the effects of stress. General levels of ego strength were shown to be the most protective for the new mother. It is likely that strength of personality predisposes an individual to percelve events as less threatening, or to perceive themselves as competent to deal with the events and enables them to take appropriate action.

Prior experience may also provide protection from 
parenting stress, so long as the experience was perceived as positive. Further, it is probably better for new mothers to have no prior experience that to have negative ones.

Tolerance for stress may be strengthened by support systems. Mothers with a supportive spouse, friends, a helpful physician or available written materials often experiences less stress. Potential support systems, such as Lamaze training, were shown to have less efficacy in avoiding stress associated with childbirth. 
REFEFENCES

Abidin. R. R. The Parenting Stress Index - Clinical trials. Paper presented at the American Psychological Association Conference, September. 1979.

Abidin. R. R. Parenting stress and the utilization of pediatric services. Children's Health Care. Fal1. 1982. Abidin. R. R. The Parenting Stress Index - Manual. Pediatric Psychology Press. 1983.

Affonso, D. Missing pieces: A study of postpartum feelings. Birth and Family Journal. 1977, 4, 159-164.

Affonso, D. and stichler, J. Exploratory study of women's reactions to having cesarean birth. Birth and Family Journal, $1978,2,88-94$.

Ainsworth. M. D., Blehar, M. C., Waters, C., and Wal1, S. Patters of attachment: a psychological study of the strange situation. Hillsdale, New Jersey: Earlbaum Associates, 1978.

Andrews, G.. Tennant, C., Hewson. D. M. \& Vailiant, G. E. Life event stress, social support, coping style, and risk of psychological impairment. Journal of Nervous and Mental Disease, 1978, 166, 307-316. Appley, M. H. and Trumbull, R. on the concept of 
Psychological Stress. In A. Monat \& R. Lazarus (Eds.), Stress and Coping: An Anthology. New York: Columbia Press, 1977.

Bel1, R. Q. The effect on the family of a limitation in coping ability in the child: A research approach and a finding. Merrill-Palmer Quarterly of Behavior and Development, 1964, 10, 129-142.

Bell. R. Q. Contributions of human infants to caregiving and social interactions. In M. Lewis \& L. Rosenblum (Eds.), The effect of the infant on its careqiver. New York: Wiley, 1974.

Bell, R. Q. Reduction of the stress in childrearing. In $L$ Levi (Eds.), Society, stress, and disease (Vol. 2). London: Oxford University Press, 1975.

Berkman, P. Life stress and psychological well-being. Journal of Health and Social Behavior, 1971, 12, 35-45.

Breznitz. S. and Goldberger, L. Stress research at a crossroads. In L. Goldberger \& S. Breznitz (Eds.), Handbook of Stress: Theoretical and Clinical Aspects. New York: Macmillan, 1982.

Brown, G. Meaning, measurement, and stress of life events. In B. S. Dohrenwend \& B. P. Dohrenwend (Eds.), Stressful life events: Their nature and effects. New York: Wiley, 1974 .

Brown, G. Social conditions related to the life stress process. In B. S. Dohrenwend \& B. P. Dohrenwend (Eds.), 
Stressful life events and their contexts. New York: Prodist, 1981 .

Broussard, E. R., \& Hartner, M. S. S. Maternal perception of the neonate as related to development. Child Psychiatry and Human Development, $1970,1,16-25$.

Burke. W. T. The development of a technique for assessing the stresses experienced by parents of young children. Unpublished doctoral dissertation. University of Virginia, 1978

Burke, W. T., \& Abidin, R. R. The development of a Parenting Stress Index. Paper presented at the American Psychological Assoclation Conference, Montreal, 1978. Cameron, $R$. and Meichenbaum, D. The nature of effective coping and the treatment of stress related problems: A cognitive-behavioral perspective. In L. Goldberger \& $S$. Breznitz (Eds.). Handbook of Stress: Theoretical and Clinical Aspects. New York: Macmillan, 1982.

Caplan. G. Support systems and community mental health. New York: Behavioral Publications, 1974.

Carey, W. B. A simplified method for measuring infant temperament. Journal of Pediatrics, 1970, 77, 188-194. Carey, W. B., and McDevitt, S. C. Revision of the Infant Temperament questionnaire. Pediatrics, 1978, 6(5), $735-739$.

Cobb.S. A model for life events and their consequences. In $B$. S. Dohrenwend \& B. P. Dohrenwend (Eds.), Stressful Iife 
events: Their nature and effect.s. New York: Wiley, 1974 . Coelho, G. V. Environmental Stress and Adolescent Coping Behavior: Key Ecological Factors in College student Adaptation. In I. G. Sarason \& C. D. Speilberger (Eds.), Stress and Anxiety Vo1 7. New York, 1980.

Cohen, N. Minimizing emotional sequelae of cesarean childbirth. Birth and Family Journal, 1977, 4, 114-119. Cohen, S. Cognitive processes as determinants of environmental stress. In I. G. Sarason \& C. D. Speilberger, Stress and Anxiety, Vol 7, New York: Columb1a, 1980.

Dyer, E. Parenthood as crisis: A re-study. Marriage and Family Living, 1963, 25, 196-201.

Endler, N. S. and Edwards, J. Stress and personality. In I. Goldberger \& S. Breznitz (Eds.), Handbook of Stress: Theoretical and Clinical Aspects. New York: Macmillan, 1982 .

Feldman. H. The effects of children on the family. In A. Michel Ed.), Eamily Issues of Employed Women in Europe and America. Leiden, The Netherlands: E. J. Bril1, 1971. Goldberg, S. Social competence in infancy: A model of parent-infant interaction. Merrill-Palmer Quarterly. $1978,23,163-178$.

Golden, R. Dohrenwend, B. S. A path analytic method for testing causal hypotheses about the life stress process. In B. S. Dohrenwend \& B. P. Dohrenwend (Eds.), StressfuI 
life events and their contexts. New York: Prodist, 1981. Goldschmidt, W. Ethology, ecology, and ethnological realities. In G. V. Coelho, D. A. Hamburg, \& J. E. Adams (Eds.), Coping and Adaptation. New York: Basic, 1974. Gore, Susan. Stress-buffering functions of social supports: An appraisal and clarification of research models. In $B$. S. Dohrenwend \& B. P. Dohrenwend (Eds.), Stressful life events and their contexts. New York: Prodist, 1981.

Gough, H. G. Manual for the California Psychological Inventory. Palo Alto, California: Consulting Psychologists Press, Inc., 1975.

Green. J. H. The relationship of stress to infant-mother attachment. Unpublished doctoral dissertation, University of Virginia, 1980.

Haan, N. The assessment of coping, defense, and stress. In L. Goldberger \& S. Breznitz (Eds.), Handbook of Stress: Theoretical and Clinical Aspects. New York: Macmillan. 1982 .

Hamilton. E. B. The relationship of maternal patterns of stress, coping, and support to quality of early infant-mother attachment. Unpublished doctoral disgertation, University of Virginia, Institute of Clinical Psychology, 1980.

Hefferin, E. Life-cycle stressors: An overview of research. In D. C. Sutterley \& G. F. Donnelly (Eds.), Coping with stress: A nursing perspective. Rockville: Aspen, 1981. 
Hobbs, D. F. Parenthood as crisis. Journal of Marriage and the Family, 1965, 27, 367.

Hobbs, D. F. Transition to parenthood: A replication and extension. Journal of Marriage and the Family, 1968, 30. 413.

Holmes, T. H., \& Masuda, M. Life change and illness susceptibility. In B. S. Dohrenwend \& B. F. Dohrenwend (eds.). Stressful life events: Their nature and effects. New York: Wiley, 1974.

Holroyd K. A. and Lazarus R. S. Stress, coping, and somatic adaptation. In L. Goldberger \& S. Breznitz (Eds.), Handbook of Stress: Theoretical and Clinical Aspects. New York: Macmillan, 1982.

Jacoby, A. Transition to parenthood: A reassessment. Journal of Marriage and the Family, 1969, 31, 720-727.

Janis, I. L. Decisionmaking under stress. In L. Goldberger \&

S. Breznitz (Eds.), Handbook of Stress: Theoretical and Clinical Aspects. New York: Macmillan, 1982.

Janis, I. L. Psychological Stress. New York: John Wiley, 1958.

Jenkins, C. D. Psychosocial modifiers of response to stress. Journal of Human Stress, $1979,3-15$.

Johnson. J. H. and Sarason, I. G. Moderator Variables in Life Stress Research. In I. G. Sarason \& C. D. Speilberger (Eds.). Stress and Anxiety Vol 6, New York: Hemisphere, 1979. 
Kornex, A. F. The effect of the infant's state, level of arousal, sex, and ontogenetic stage on the caregiver. In M. Lewis \& L. Rosenblum (Eds.). The effect of the infant on its caregiver. New York: Wiley, 1974.

LaFiosca, T. The relationship of parental stress to anxiety. approval motivation, and children's behavior problems. Unpublished doctoral dissertation, University of Virginia, 1981

Lagercrantz, E., \& Lagercrantz, R. The mother and her first born. In L. Levi (Ed.), Society, stress, and disease (Vol. 2). London: Oxford University Press, 1975.

Leifer, M. Psychological changes accompanying pregnancy and motherhood. Genetic Psychology Monographs, 1977, 95, $55-96$

LeMasters, E. Parenthood as crisis. Marriage and Family Eiving, 1957, 19, 352-355.

Levy, J. C. Vulnerable children: Parents' perspectives and the use of medical care. Pediatrics, $1980,65,956-963$. Lieberman. M. A. The effects of social supports on responses to stress. In L. Goldberger \& S. Breznitz (Eds.), Handbook of Stress: Theoretical and Clinical Aspects. New York: Macmilian, 1982.

Lipson, J. G. and Tilden. V. P. Psychological integration of the cesarean birth experience. American Journal of Orthopsychiatry. 1980, 50, 598-609.

Littman, B., \& Parmelee, A. H. Medical correlates of infant 
development. Pediatrics, 1978, 60, 470-474.

Lazarus, R. S. Psychological Stress and the Coping Process. New York: McGraw-Hill, 1966.

Lozoff, B., Brittenham, G. M., , M. A., Kennell, J. H., \& Klaus, M. H. The mother-newborn relationship Limits of adaptability. Journal of Pediatrics, 1977, 91, 1-12.

Magnusson, D. Situational determinants of stress: An interactional perspective. In L. Goldberger \& $\mathrm{S}$. Breznitz (Eds.), Handbook of Stress: Theoretical and Clinical Aspects. New York: Macmillan, 1982.

Marut, J. and Mercer, R. A comparison of primipara's perception of vaginal and cesarean births. Nursing Research, 1979, 28, 260-266.

Mcgrath, J. E. A conceptual formulation for research in stress, In J. E. McGrath (Ed.), Social and psychological factors in stress. New York: Holt, Rinehart, \& Winstron, 1970.

Mechanic, C. Influence of mothers on their children's health attitudes and behavior. Pediatrics, 1964, 33, 444 . Mechanic, D. Students Under Stress: A Study in the Social Psychology of Adaptation. Madison: University of Wisconsin Press, 1962, 1978.

Metz, J. M., Allen, C. M., Barr, G., \& Shinefield, N. A pediatric screening examination of psychosocial problems. Pediatrics, 1976, 58, 595-606.

Mevs, L. The current status of cesarean section and today's 
maternity patient. Journal of Obstetrics and Gynecological Nursing. $1977,6,44-47$.

Meyers, J. K., Lindenthal, J. J., \& Pepper, M. P. Social class, life events, and psychiatric symptoms: A longitudinal study. In B. S. Dohrenwend and B. P. Dohrenwend (Eds.), Stressful life events: Their nature and effects. New York: Wiley, 1974.

Moos, R. H. and Billings, A. G. Conceptualizing and measuring coping resources and processes. In L. Goldberger \& S. Breznitz (Eds.), Handbook of Stress: Theoretical and Clinical Aspects. New York: Macmillan, 1982.

Nuckolls, K. B., Cassel, J., \& Kaplan, B. H. Psychosocial assets, life crisis, and the prognosis of pregnancy. American Journal of Epidemiology. 1972, 95, 431-441.

Pearlin, L. I. The social context of stress. In L. Goldberger \& S. Breznitz (Eds.), Handbook of Stress: Theoretical and Clinical Aspects. New York: Macmillan, 1982.

Rahe, R. H. The pathway between subjects' recent life changes and their near future illness reports: Representative results and methodological issues. In B. S. Dohrenwend \& B. P. Dohrenwend (Eds.), Stressful life events: Their nature and effects. New York: Wiley, 1974.

Robson, K. S., \& Moss, H. A. Patterns and determinants of maternal attachment. Journal of Pediatrics, 1970, 77. $976-985$

Roghmann, K. J., \& Haggerty, R. J. Daily stress, illness, and 
use of health services in young families. Pediatric Research. I, 520-526.

Rossi, A. Transition to parenthood: A reassessment. Journal of Marriage and the Family, 1974, 31, 720.

Russell, C. Transition to parenthood: Problems and gratifications. Journal of Marriage and the Family, $1974,36,294-302$.

Sarason, I. G. Life stress, self-preoccupation, and social supports. In I. G. Sarason \& Speilberger C. D. (Eds.), Stress and Anxiety Vo1 7, New York: Hemisphere, 1980. Scholom, A., Zucker, R. A., \& Stollak, G. E. Relating early child adjustment to infant and parent temperament. Journal of Abnormal Child Psychology. 1979, I, 297-308.

Scott, D. W., Oberst, M. T., \& Dropkin, M. A stress-coping model. In Sutterley, D. C., \& Donnelly, G. F (Eds.), Coping with Stress: A Nursing Perspective. Rockville: Aspen, 1981 .

Selye, H. Stress without distress. Philadelphia: Lippincott, 1974 .

Selye, H. History and present status of the stress concept. In L. Goldberger \& S. Breznitz (Eds.). Handbook of Stress: Theoretical and Clinical Aspects. New York: Macmillan, 1982 .

Stokols, D. A congruence analysis of human stress. In I. G. Sarason \& C. D. Speilberger (Eds.). Stress and Anxiety Vo1 6. New York: Hemisphere, 1979. 
Stott, D. H. Follow-up study from birth of the effects of - prenatal stresses. Developmental Medicine and Child Neurology, 1973, 15, 770-787.

Thomas, A., Chess, S.. \& Birch, H. Temperament and behavior disorders in children. New York: New York University Press, 1968.

Trowel1 J. Emergency caesarian section: Effects on the mother-child relationship. Early Human Development. $1982, \underline{7}, 41-51$

Wright, B. M.. \& Zucker, R. A. Parental responses to competence and trauma in infants with reproductive causalty. Journal of Abnormal Child Psychology, 1980, 8 . $385-395$.

Zimmerman, J. L. The relationship between support systems and stress in families with a handicapped child. Unpublished doctoral dissertation, University of Virginia, 1980. 
APPENDIX A

December. 1983

Qname

Gaddr 1

Gaddr 2

Qcity, Gstate azip

Dear @ref:

Your pediatrician and I are inviting you to participate in a study of stress in mothers of young infants. Those of us who work with mothers of young infants have long been aware that it is not easy to have a new baby and are interested in discovering those factors that influence the stress.

We are asking you to complete the enclosed questionaires which will probabiy take you two hours or a litte less. Realizing that your time is in short supply now. I would like to explain why all this material is necessary. Stress is a complex problem that is influenced by the expectations a person has. the meaning an event has to them personally, how prolonged or severe the stressful event is and the personal and social assets a person has that help to cope with it. Knowing all these things provides an understanding of the situation in context. Only when we know the context can we arrive at conclusions about what kind of intervention would really help.

The packet consists of five items. The directions are printed on each item. I will clarify that the California Psychological Inventory is an instrument designed to measure personality traits in normal individuals. It has of ten been used to measure traits in various occupational groups, such as medical students. The responses to this questionaire go on the answer sheet provided.

The Soclal Support Checklist may need a little extra explanation also. There is a column labeled "support code". The codes to be used are indicated on the second sheet of the checklist document.

Please remember to sian the Informed Consent and return everything in the packet except this letter. 
In appreciation of your contribution to this research, you will recelve a book entitled Learning Through Plav, by Paul Chance. Ph.D. The Foreword of the book states that "for children, play is not a spare-time occupation." Play lies at the very core of human behavior and development. There is growing evidence that indicates play begins early in the first year, and that an environment conducive to play relates well to the chlld's intelifgence.

When you return the completed materials to me, I will mail the book to you. Please allow me three weeks for this process.

If you do not want to participate, please return the materials in the enclosed envelop.

Thank you for your help in this project. I hope you will find the experience interesting.

Very truly yours.

Janet $B$. Younger 
APPENDIX B

Dear Parent:

I am cooperating with the Parenting Stress Research Project being conducted by Janet $B$. Younger of the University of Virginia. The project is designed to determine the factors that create stress for parents of young infants and factors that protect parents against those stresses. Since the only source of this information is mothers such as yourself, we are asking for your help.

Participation in the project would require that you spend about two hours, or a little less. completing several questionaires. You would have two or three weeks to complete them. The only contact you wlll receive concerning this project will be by ma11. That is, there will be no phone calls or other types of communication.

I believe that this project will provide researchers and health care providers with needed information about the stresses of childbearing and suggest ways we can be of more assistance to mothers such as yourseif.

If, however, you don't want to participate, simply return the materials as requested. This will in no way affect your child's health care. In fact. I will not even be aware of which of the parents in my practice participate. Please let me know if you have any questions about your participation.

Yours truly, 


\section{APPENDIX C}

\section{Support System Checklist}

A. How helpful are each of the following to you as a parent? Please circle the response that best describes how helpful. Cross out any sources of help that are not available to you.

\section{Source}

1. My spouse

2. My mother

3. My father

4. Private Psychologist

5. Frlends

6. Written Material (books, mag., news.)

7. My mother-in-law

8. My father-1n-law

9. School programs

10. My Other Children

11. TV, radio, lectures

12. Social Services

(counseling, legal)
Not at all Moderately Extremely Support helpful helpful helpful code 
B. What kind of support does each provide? (pick one and insert by each number on the first page)

1. Emotional support = the providing of empathy, understanding, acceptance, encouragement and warmth, as well as listening and giving overall moral support to help you in coping with everpday difficulties or stressful situations.

2. Advice-Feedback = providing information or suggestions on how to achieve a certain goal or deal with a certain problem (e.g., provides advice) and/or comments on whether you are meeting expectations or requirements of a certain goal (e.g. letting you know how you are doing on a certain jobl.

3. Tangible support = the providing of money (as a loan or gift) or other material resources (e.g. food. clothing, etc. lespecially when needed.

4. General services = the providing of actual physical help in the carrying out of family duties (e.g. shopping, babysitting, or helping with other household duties, etc.). 


\section{APPENDIX D}

\section{Background Information}

1. Please provide the name of the hospital/location where the delivery took place

2. How many other children have you delivered?
a. 0
(1)
b. 1
(2)
c. 2
d. 3
(4)
e. more than 3
(5)

3. To what extent would you agree with the statement. "This pregnancy was planned."
a. strongly agree
(1)
b. agree
(2)
c. not sure
d. disagree
e. strongly disagree
(5)

4. To what extent would you agree with the statement, "This pregnancy was wanted."
a. strongly agree
(1)
b. agree
c. not sure
d. disagree
e. strongly disagree
(5)

5. To what extent would you agree with the statement. "This pregnancy was stressful."
a. strongly agree
(5)
b. agree
c. not sure
d. disagree
e. strongly disagree
(1)

6. To what extent would you agree with the statement, "This labor and delivery was stressful."
a. strongly agree
(5)
b. aqree
(4)
c. not sure
(3)
d. disagree
(2)
e. strongly disagree
(1) 
7. Compare this pregnancy to prior pregnancies:

a. This pregnancy was similar to at least one prior preqnancy and the prior experience was a positive one. (5)

b. This pregnancy was similar to at least one prior pregnancy and the prior experience was a neqative one. (1)

c. I have no prior experience.

d. Th1s pregnancy was not similar to prior experience, but my prior experience was a positive one. (2)

e. This pregnancy was not similar to prior experience. but my prior experience was a negative one. (3)

8. Compare this labor and delivery to prior experiences:

a. This labor and delivery was similar to at least one prior experience and the prior experience was a positive one. (5)

b. This labor and delivery was simflar to at least one prior experience and the prior experience was a negative one. (1)

c. I have no prior experience.

d. This labor and delivery was not similar to prior experience, but the prior experience was positive. (2)

e. This labor and delivery was not similar to prior experience, but the prior experience was negative. (3)

9. To what extent, if any, did you use the Lamaze method of childbirth.

a. I am/was unfamiliar with Lamaze technique. (1)

b. I am familiar with the Lamaze method, but did not attend classes. (2)

c. I attended one Lamaze class. (3)

d. I attended between 2 and 4 Lamaze classes. (4)

e. I attended at least 5 Lamaze classes. (5)

10. What was the baby's birthdate?

11. Please list any complications you had with your pregnancy and indicate whether they required hospitalization.

12. Please list any complications you had with your labor and delivery. 
13. Indicate the nature of the delivery.

1. vaginal delivery (1)

2. your first caesarean section (3)

3. a repeat caesarean section (2)

14. Are you now a working mother? yes no (Circle)

15. Do you anticipate being a working mother? yes no

16. Were you employed during the last six months? yes no

17. Have you ever been employed full-time for a period of at least two years? yes (2) no (1)

18. Have you invested as much as two years training in a specific occupation? yes (2) no (1) 


\section{APPENDIX E}

Informed Consent

I understand that the purpose of this study is to learn about the stress new parents experience. I realize that I am not required to take part in this project, and that, if I do not particlpate, that will not affect the care given my child by my pediatrician.

I give permission for my medical records and my child's medical records to be reviewed for the purposes described to me for this study.

I understand that all information from the records and from the questionalres will be kept strictly confidential.

I understand that I may withdraw from this study at any time.

date

signature 


\section{APPENDIX F}

Intercorrelations of CPI Sub-classes

Total Scoke and Combined Predicted Scales

\begin{tabular}{|c|c|c|c|c|c|c|}
\hline CPI Sub-class & II & III & IV & (5) & $(6)$ & \\
\hline $\begin{array}{l}\text { Poise, Ascendancy, } \\
\text { Interpersonal Adequacy } \\
\text { I }\end{array}$ & $\star$ & & & & & \\
\hline $\begin{array}{l}\text { Socialization. } \\
\text { Responsibility, Intra- } \\
\text { Personal Values } \\
\text { II }\end{array}$ & .57 & $\star$ & & & & \\
\hline $\begin{array}{l}\text { Achievement Potential } \\
\text { III }\end{array}$ & .71 & .87 & $\star$ & & & \\
\hline $\begin{array}{l}\text { Intellectual and } \\
\text { Interest Modes } \\
\text { IV }\end{array}$ & .38 & .41 & .52 & $\star$ & & \\
\hline $\begin{array}{l}\text { Combined, Predicted } \\
\text { Scales } \\
\text { (5) }\end{array}$ & .90 & .90 & .92 & .52 & 夫 & \\
\hline $\begin{array}{l}\text { Total CPI } \\
\text { ( } 6)\end{array}$ & .85 & .83 & .95 & .55 & .99 & * \\
\hline
\end{tabular}




\section{APPENDIX G}

Intercorrelations of Stressor Variables

\begin{tabular}{lllllllllll}
\hline Stressor Variable & 1 & 2 & 3 & 4 & 5 & 6 & 7 & 8 \\
\hline
\end{tabular}

Life stress

(1)

$\star$

Planned Pregnancy

(2)

$-.01 \star$

Wanted Pregnancy

(3)

$.00 .56 \star$

Stress Pregnancy

(4)

$.01 .01 \quad .10 \star$

Stress L\&D

(5)

$.23-.15-.06 \quad .29 \star$

Complications of

Pregnancy (6)

$\begin{array}{lllll}-.14 & .11 & .19 & .27 & .05\end{array}$

Complication of

L\&D (7)

$$
\begin{array}{llllll}
.15 & -.08 & -.14 & .25 & .26 & .26
\end{array} \text { * }
$$

Method of

Delivery ( 8 )

$\begin{array}{llllllll}-.04 & -.05 & -.14 & .10 & .11 & .01 & .57 & \star\end{array}$ 
APPENDIX $\mathrm{H}$

Intercorrelations of Social Support Variables

Vartable

$(1$

(2) (3) (4

$(5$

(6)

(7)

\section{Spouse}

(1)

$\star$

Friends

(2)

$.16 \star$

Written Matter

(3)

$.09 .19 \star$

Other Parents

(4)

$.25 \quad .40 \quad .46 \quad \star$

My Mother

(5)

$\begin{array}{lllll}.14 & .04 & .07 & .00 & \end{array}$

other Own Fam1ly

(6)

$\begin{array}{lllll}.03 & .26 & .09 & .36 & .28\end{array}$

Medical Doctor

(7)

$\begin{array}{llllll}.25 & .13 & .44 & .35 & .35 & .26\end{array}$


APPENDIX I

Intercorrelations of Experience Variables

\begin{tabular}{|c|c|c|c|c|c|c|c|c|c|}
\hline Vartable & (1) & $(2)$ & (3) & (4) & (5) & $(6)$ & $(7)$ & $(8)$ & (9) \\
\hline $\begin{array}{l}\text { Age } \\
\text { (1) }\end{array}$ & $\star$ & & & & & & & & \\
\hline $\begin{array}{l}\text { Mother's } \\
\text { Education (2) }\end{array}$ & .42 & $\star$ & & & & & & & \\
\hline $\begin{array}{l}\text { Father's } \\
\text { Education (3) }\end{array}$ & .37 & .61 & $\star$ & & & & & & \\
\hline $\begin{array}{l}\text { Other Children } \\
\text { (4) }\end{array}$ & .32 & -.11 & .05 & $\star$ & & & & & \\
\hline $\begin{array}{l}\text { Prior Pregnancy } \\
\text { (5) }\end{array}$ & .01 & .05 & .05 & -.24 & $\star$ & & & & \\
\hline $\begin{array}{l}\text { Prior L\&D } \\
(6)\end{array}$ & -.04 & .10 & .07 & -.28 & .40 & * & & & \\
\hline $\begin{array}{l}\text { Lamaze Training } \\
(7)\end{array}$ & .07 & .37 & .38 & -.19 & .09 & .06 & $\star$ & & \\
\hline$\underset{(8)}{\text { Employed } 2 \text { Yrs }}$ & .27 & .36 & .21 & -.23 & .19 & .08 & -.19 & $\star$ & \\
\hline $\begin{array}{l}\text { Trained } 2 \text { Yrs } \\
(9)\end{array}$ & .20 & .32 & .17 & -.21 & .03 & .07 & -.31 & .50 & $\star$ \\
\hline
\end{tabular}




\section{APPENDIX J}

Descriptive Summary of Reduced Variables

\begin{tabular}{lrrrr}
\hline Variable & Mean & SD & Minimum & Maximum \\
\hline Total Parenting Stress & 236.2 & 38.3 & 131 & 351 \\
Parent Domain Stress & 129.4 & 23.9 & 56 & 198 \\
Child Domain Stress & 106.8 & 18.4 & 65 & 187 \\
Pregnancy Stress & .0 & 2.5 & 4 & 17 \\
L\&D Stress & .0 & 2.2 & 3 & 11 \\
Primary Social Support & 15.7 & 3.4 & 7 & 32 \\
Secondary Social Support & 17.5 & 4.0 & 2 & 26 \\
Specif1c Prior Exper1ence & .0 & 1.7 & 3 & 10 \\
General Experience & .0 & 3.9 & 23 & 53 \\
Total Personality & 432.1 & 65.6 & 275 & 560 \\
\end{tabular}




\section{APPENDIX $\mathrm{K}$}

Descriptive Summary of CPI

Variable

Mean

\$D

Minimum Maximum

Dominance

Capacity for status

Soclability

Social Presence

Self Acceptance

We11 Being

Class I

Responsibility

Socialization

Self Control

Tolerance

Good Impression

Communality

Class II

Achievement Conformity

Achievement Independence

Intellectual Efficiency

Class III

Psychological Mindedness

Flexibility

Femininity

Total Personality

\section{5}

17.5

23.0

33.9

20.5

33.9

153.5

27.9

35.9

28.8

20.3

14.9

25.8

153.2

25.6

19.8

35.4

80.4

10.9

9.1

23.2

432.1
6.9

4. 9

5.4

6.0

3.7

5.8

26.8

5.9

6.5

7.9

5.8

5.7

2.9

27.2

6.2

4.8

7.1

16.6

2.9

3.4

4.2

65.6

275
29

29

33

46

27

42

208

42

53

45

31

31

30

203

10

89

37

30

48

111

16

18

32

13

560 
APPENDIX L

Descriptive summary of PSI

\begin{tabular}{lrrrr}
\hline Variable & Mean & SD & Minimum & Maximum \\
& & & & \\
\hline Adaptability & 26.6 & 5.7 & 15 & 49 \\
Acceptability & 13.1 & 3.5 & 7 & 26 \\
Demandingness & 19.3 & 5.3 & 9 & 38 \\
Mood & 11.1 & 3.2 & 5 & 19 \\
Distractibility & 26.4 & 4.5 & 15 & 41 \\
Reinforces Mother & 10.2 & 3.1 & 5 & 20 \\
Child Domain & 106.8 & 18.4 & 65 & 187 \\
& 21.0 & 5.5 & 9 & 37 \\
Depression & 14.8 & 3.0 & 8 & 26 \\
Attachment & 19.2 & 5.5 & 7 & 35 \\
Role Restriction & 29.3 & 7.3 & 7 & 28 \\
Competence & 13.8 & 3.9 & 6 & 34 \\
Isolation & 18.3 & 5.0 & 8 & 29 \\
Spouse & 13.1 & 3.6 & 5 & 198 \\
Health & 129.4 & 24.0 & 56 & 351 \\
Parent Domain & 236.2 & 38.3 & 131 & 37 \\
Total Stress & 6.9 & 5.9 & 4 & \\
Life Stress & & & & \\
& & & & \\
\hline
\end{tabular}


APPENDIX M

Descriptive Summary of Social support Variables

\begin{tabular}{|c|c|c|c|c|c|c|c|c|}
\hline \multirow[t]{2}{*}{ Variable } & \multirow[b]{2}{*}{$(0)$} & \multicolumn{7}{|c|}{ Frequencies/Percentages } \\
\hline & & (1) & (2) & (3) & (4) & $(5)$ & $(6)$ & (7) \\
\hline Spouse & 6 & 5 & 2 & 3 & 12 & 15 & 19 & 39 \\
\hline Mother & 10 & 3 & 4 & 4 & 24 & 10 & 20 & 26 \\
\hline Father & 29 & 10 & 9 & 9 & 14 & 12 & 10 & 8 \\
\hline Friends & 2 & 2 & 10 & 18 & 35 & 16 & 9 & 9 \\
\hline Psychologist & 96 & 1 & 0 & 1 & 0 & 1 & 0 & 2 \\
\hline Written Mat & 2 & 2 & 9 & 17 & 24 & 15 & 20 & 12 \\
\hline TV.Radio & 15 & 12 & 18 & 22 & 20 & 5 & 6 & 3 \\
\hline Mother-in-1aw & 25 & 8 & 7 & 20 & 17 & 10 & 9 & 5 \\
\hline Neighbors & 16 & 17 & 17 & 14 & 17 & 12 & 4 & 4 \\
\hline Father-in-law & 44 & 12 & 9 & 12 & 10 & 7 & 3 & 4 \\
\hline Other Parents & 2 & 1 & 9 & 11 & 24 & 28 & 15 & 11 \\
\hline School Program & 80 & 6 & 1 & 3 & 3 & 5 & 0 & 3 \\
\hline Other Family & 10 & 5 & 3 & 21 & 25 & 15 & 12 & 10 \\
\hline Other Child & 60 & 4 & 5 & 7 & 7 & 8 & 5 & 5 \\
\hline Spouse Family & 20 & 17 & 9 & 17 & 20 & 8 & 6 & 4 \\
\hline Social Service & 79 & $9:$ & 1 & 1 & 4 & 3 & 1 & 3 \\
\hline $\mathrm{MD}$ & 7 & 2 & 7 & 9 & 21 & 18 & 19 & 18 \\
\hline Reliqion & 37 & 20 & 4 & 11 & 14 & 8 & 4 & 3 \\
\hline
\end{tabular}

Note. Since these frequencies were calculated on 101 subjects. the frequency percentage. when rounded, almost always equals the absolute frequency. 
APPENDIX N

Descriptive Summary of Stressor Variables

"This preqnancy was planned."

Strongly agree Agree Not sure Disagree Strongly disagree
46
14
10
22
9

"This pregnancy was wanted."

Strongly agree Agree Not sure Disagree Strongly disagree 75

15

6

4

1

"This preqnancy was stressful."

Strongly agree Agree Not sure Disagree Strongly disagree
13
29
11
33
15

"This labor and delivery was stressful."

Strongly agree Agree Not sure Disagree Strongly disagree 9

28

8

42

14

Complications of Pregnancy

None Minor Major

$\begin{array}{lll}63 & 27 & 11\end{array}$

Complications of Labor and Delivery

$\begin{array}{ccc}\text { None } & \text { Minor } & \text { Major } \\ 54 & =31 & 16\end{array}$

Method of Delivery

Vaginal delivery

82

First Caesarean section

12

Repeat Caesarean section 
APPENDIX 0

Descriptive Summary of Experience Variables

Variable

Frequency

How many other children have you delivered?

$\begin{array}{ll}0 & 59 \\ 1 & 29 \\ 2 & 8 \\ 3 & 4 \\ \text { more than } 3 & 1\end{array}$

Compare this pregnancy to prior pregnancies:

This pregnancy was similar to at least one prior pregnancy and the prior experience was a positive one 17

This pregnancy was similar to at least one prior pregnancy and the prior experience was a negative one. 4

I have no prior experience.

This pregnancy was not similar to prpior experience. but my prior experience was a positive one.

This pregnancy was not similar to prior experience, but my prior experience was a negative one.

Compare this L\&D to prior experiences:

This L\&D was similar to at least one prior experience and the prior experlence was a positive one 16

The L\&D was similar to at least one prior experience and the prior experience was a negative one. 2

I have no prior experience.

This L\&D was not similar to prior experience but the prior experfence was positive.

This L\&D was not similar to prior experience but the prior experience was negative.

\section{Lamaze method of childbirth}

I am/was unfamilar with Lamaze technique.

I am familiar with the Lamaze method. but did not attend classes.

I attended one Lamaze class

I attended between 2 and 4 lamaze classes.

I attended at least 5 Lamaze classes. 
Are vou now a working mother?

Yes

Have you ever been employed full-time for a period of at least two years?

Yes

91

No

Have you invested as much as two years training

in a specific occupation?

Yes

75

No 
APPENDIX $P$

Major Obstetric Complications

\author{
Cephalopelvic Disproportion \\ Blood group incompatibility \\ Drug abuse \\ Hemoglobin $<12 \mathrm{gm}$. \\ Multiple birth \\ Second stage $<10$ or $>120$ min \\ Meconium stained anmionic fluid \\ Fetal presentation other than vertex \\ Nuchal cord \\ Cord prolapse \\ Placental infarction \\ Placenta previa or abruptio \\ Newborn resuscitation required \\ Apgar $<7$. \\ Eclampsia
}

